\title{
Bioprocess Design and Economics
}

\author{
by \\ Demetri Petrides, Ph.D. \\ President \\ INTELLIGEN, INC. \\ 2326 Morse Avenue \\ Scotch Plains, NJ 07076 \\ Tel: (908) 654-0088 \\ Fax: (908) 654-3866 \\ Email: dpetrides@intelligen.com \\ http://www.intelligen.com
}

An improved version of this document can be found in the following textbook:

Bioseparations Science and Engineering

ROGER G. HARRISON, University of Oklahoma, PAUL W. TODD, Chief Scientist, Space Hardware Optimization Technology, Inc., SCOTT R. RUDGE, Vice President of Operations for FeRx, Inc., and DEMETRI PETRIDES, President, Intelligen, Inc.

http//www oup-usa.org/isbn/0195123409 htm

Oxford University Press, 2003

ISBN 0-19-512340-9

Copyright @ 2000, by Demetri Petrides ALL RIGHTS RESERVED. 


\section{Chapter 11. Bioprocess Design and Economics}

This chapter aims to teach students and practicing engineers the fundamentals of bioprocess design with emphasis on bioseparation processes. It is an attempt to combine the information presented in previous chapters and utilize it in the context of integrated processes. The ultimate objective is to enable the reader to efficiently synthesize and evaluate integrated bioseparation processes.

Given a product and a desired annual production rate (plant throughput) bioprocess design endeavors to answer the following questions: What are the required amounts of raw materials and utilities? What is the required size of process equipment and supporting utilities? Can the product be produced in an existing facility or a new plant is required? What is the total capital investment? What is the manufacturing cost? What is the optimum batch size? How long does a single batch take? How much product can be generated per year? During the course of a batch what is the demand for various resources (e.g., raw materials, labor, utilities, etc.)? What is the total amount of resources consumed? Which process steps or resources constitute bottlenecks? What changes can increase throughput? What is the environmental impact of the process (i.e., amount and type of waste materials)? Which design is the "best" among several plausible alternatives?

\subsection{DEFINITIONS AND BACKGROUND}

Process design is the conceptual work done prior to building, expanding or retrofitting a process plant. It consists of two main activities, process synthesis and process analysis. Process synthesis is the selection and arrangement of a set of unit operations (process steps) capable of producing the desired product at an acceptable cost and quality. Process analysis is the evaluation and comparison of different process synthesis solutions. In general, a synthesis step is usually followed by an analysis step, and the results of analysis determine the subsequent synthesis step. Process design and project economic evaluation require integration of knowledge from many different scientific and engineering disciplines and are carried out at various levels of detail. Table 11-1 presents a common classification of design and cost estimates and typical engineering cost for a \$50 million plant (Douglas, 1988; Frohlich, 1999).

Figure 11-1 presents the need for various types of design estimates during the lifecycle of product development and commercialization (Frohlich, 1999). The trapezoidal shape of the graph represents the drastic reduction in product candidates as we move from feasibility studies to commercialization. In fact, the chances of commercialization at the research stage for a new product are only about 1 to $3 \%$, at the development stage they are about 10 to $25 \%$, and at the pilot plant stage they are about 40 to $60 \%$ (Douglas, 1988). 
Table 11-1 Types of design estimates

\begin{tabular}{|c|l|c|c|}
\hline Level & Type of Estimate & Accuracy & Cost (\$1000) \\
\hline 1. & $\begin{array}{l}\text { Order-of-Magnitude estimate (ratio estimate) based on } \\
\text { similar previous cost data. }\end{array}$ & $\leq 50 \%$ & - \\
\hline 2. & $\begin{array}{l}\text { Project Planning estimate (budget estimation) based on } \\
\text { knowledge of major equipment items. }\end{array}$ & $\leq 30 \%$ & $20-40$ \\
\hline 3. & $\begin{array}{l}\text { Preliminary Engineering (scope estimate) based on } \\
\text { sufficient data to permit the estimate to be budgeted. }\end{array}$ & $\leq 25 \%$ & $50-100$ \\
\hline 4. & $\begin{array}{l}\text { Detailed Engineering (capital approval stage) based on } \\
\text { almost complete process data. }\end{array}$ & $\leq 15 \%$ & $100-200$ \\
\hline 5. & $\begin{array}{l}\text { Procurement and Construction (contractor's estimate) } \\
\text { based on complete engineering drawings, specifications, } \\
\text { and site surveys. }\end{array}$ & $\leq 10 \%$ & $3,000-7,000$ \\
\hline
\end{tabular}

Order-of-magnitude estimates are usually practiced by experienced engineers who have worked on similar projects in the past. They take minutes or hours to complete but the error in the estimate can be as high as $50 \%$. Most engineers employed by operating companies usually perform level 2 and 3 studies. Such studies take days or weeks to complete using appropriate computer aids. The main objective of such studies is to evaluate alternatives and pinpoint the most cost-sensitive areas - the economic "hot-spots" - of a complex process. The results of such analyses are used to plan future research and development and to generate project budgets.

Level 4 and 5 studies are usually performed by engineering and construction companies that are hired to build new plants for promising new products that are at an advanced stage of development. Such estimates are beyond the scope of this chapter. Instead, the focus of the material in the rest of this chapter will be on level 1,2, and 3 studies. It should also be noted that opportunities for creative process design work are usually limited to preliminary studies. By the time detailed engineering work is initiated, a process is more than $80 \%$ fixed. Furthermore, the vast majority of important decisions for capital expenditures and product commercialization are based on results of preliminary process design and cost analysis. This explains why it is so important for a new engineer to master the skills of preliminary process design and cost estimation.

Environmental impact assessment is an activity closely related to process design and cost estimation. Biochemical plants generate a wide range of liquid, solid, and gaseous waste streams that require treatment prior to discharge. The cost associated with waste treatment and disposal has skyrocketed in recent years due to increasingly stricter environmental regulations. This cost can be reduced through minimization of waste generation at the source. However, generation of waste from a chemical or biochemical process is dependent upon the process design and the manner in which the process is operated. Thus, reducing waste in an industrial process requires intimate knowledge of the process technology, in contrast to waste treatment which essentially is an add-on at the end of the process. In addition, minimization of waste generation must be considered by process engineers at the early stages of process development. Once a process has undergone significant development it is difficult and costly to make major changes. Furthermore, 
regulatory constraints that are unique to the pharmaceutical industry restrict process modifications once clinical efficacy of the drug is established. These are only some of the reasons that process synthesis must be considered not only during, but before, the selection of unit operations for individual steps.

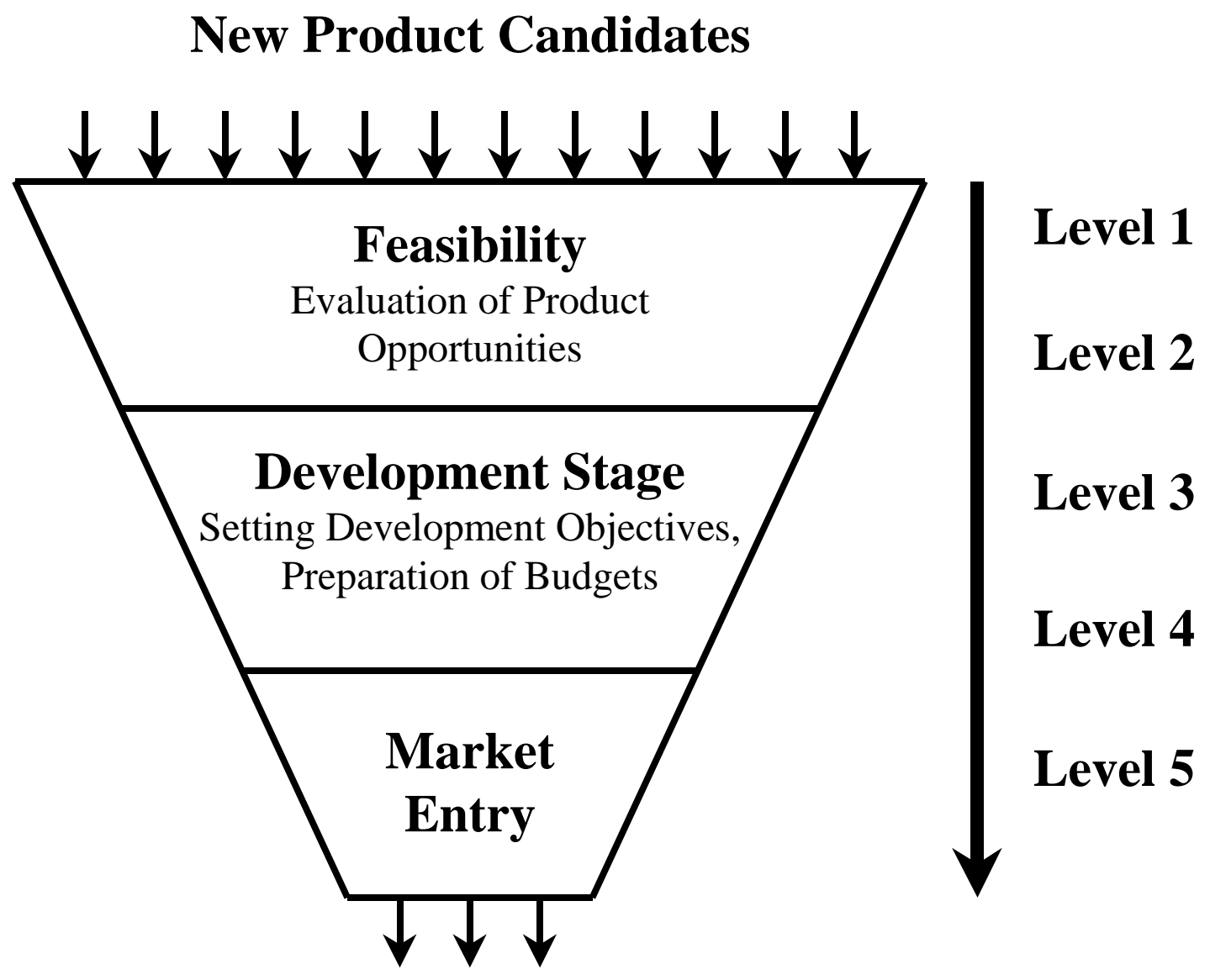

\section{Commercial Products}

Figure 11-1 Types of design estimates during the lifecycle of a product.

\subsection{SYNTHESIS OF BIOSEPARATION PROCESSES}

The development of a flowsheet for the recovery and purification of a biological product is a creative process that draws on the experience and imagination of the engineer. Attempts have been made to capture that experience on the computer in the form of expert systems (Asenjo and Maugeri, 1992; Leser and Asenjo, 1992; Petrides et al., 1989; Petrides, 1994) and automate to some extent the process synthesis tasks. Experienced engineers heavily rely on certain rules of 
thumb, also known as heuristics, for putting together the skeleton of a recovery and purification process. A few such heuristics follow:

1) Remove the most plentiful impurities first.

2) Remove the easiest-to-remove impurities first.

3) Make the most difficult and expensive separations last.

4) Select processes that make use of the greatest differences in the properties of the product and its impurities.

5) Select and sequence processes that exploit different separation driving forces.

Figure 11-2 provides a generalized structure for putting together an initial block diagram representation of a recovery process (Petrides et al., 1989). For each product category (intracellular or extracellular) several branches exist in the main pathway. Selection among the branches and alternative unit operations is based on the properties of the product, the properties of the impurities, and the properties of the producing microorganisms, cells or tissues. Bioprocess synthesis thus consists of sequencing steps according to the five heuristics and the structure of Figure 11-2. The majority of bioprocesses, especially those employed in the production of highvalue, low-volume products operate in batch mode. Continuous bioseparation processes are utilized in the production of commodity biochemicals, such as organic acids and ethanol.

\subsubsection{Primary Recovery Stages}

Primary recovery comprises the first steps of downstream processing where some purification and broth volume reduction occurs. According to Figure 11-2, the selection of the first step depends on whether the product is intracellular (remains inside the microorganism after its expression) or extracellular (secreted into the solution). Almost all low molecular weight and many high molecular weight bioproducts are extracellular. Their recovery and purification is easier compared to intracellular products due to the lower amount of impurities present. Most recombinant eukaryotic proteins produced by prokaryotic microorganisms are intracellular products (see Chapter 2 for definitions of prokaryotic and eukaryotic cells). They accumulate inside the host cell in either native or denatured form; the denatured intracellular products often form insoluble inclusion bodies (IB's). A brief review of the most common primary recovery steps (described in chapters 2,3 and 4) follows, and various rationales for unit operation selection are included.

\section{INTRACELLULAR PRODUCTS}

Cell Harvesting. The first purification step for intracellular products is cell harvesting. Removal of the extracellular liquid is in agreement with the first general heuristic - Remove the most plentiful impurities first.

As seen in Figure 11-2, centrifugation and membrane filtration (both micro- and ultrafiltration) are the only techniques used for large-scale cell harvesting. As explained in 


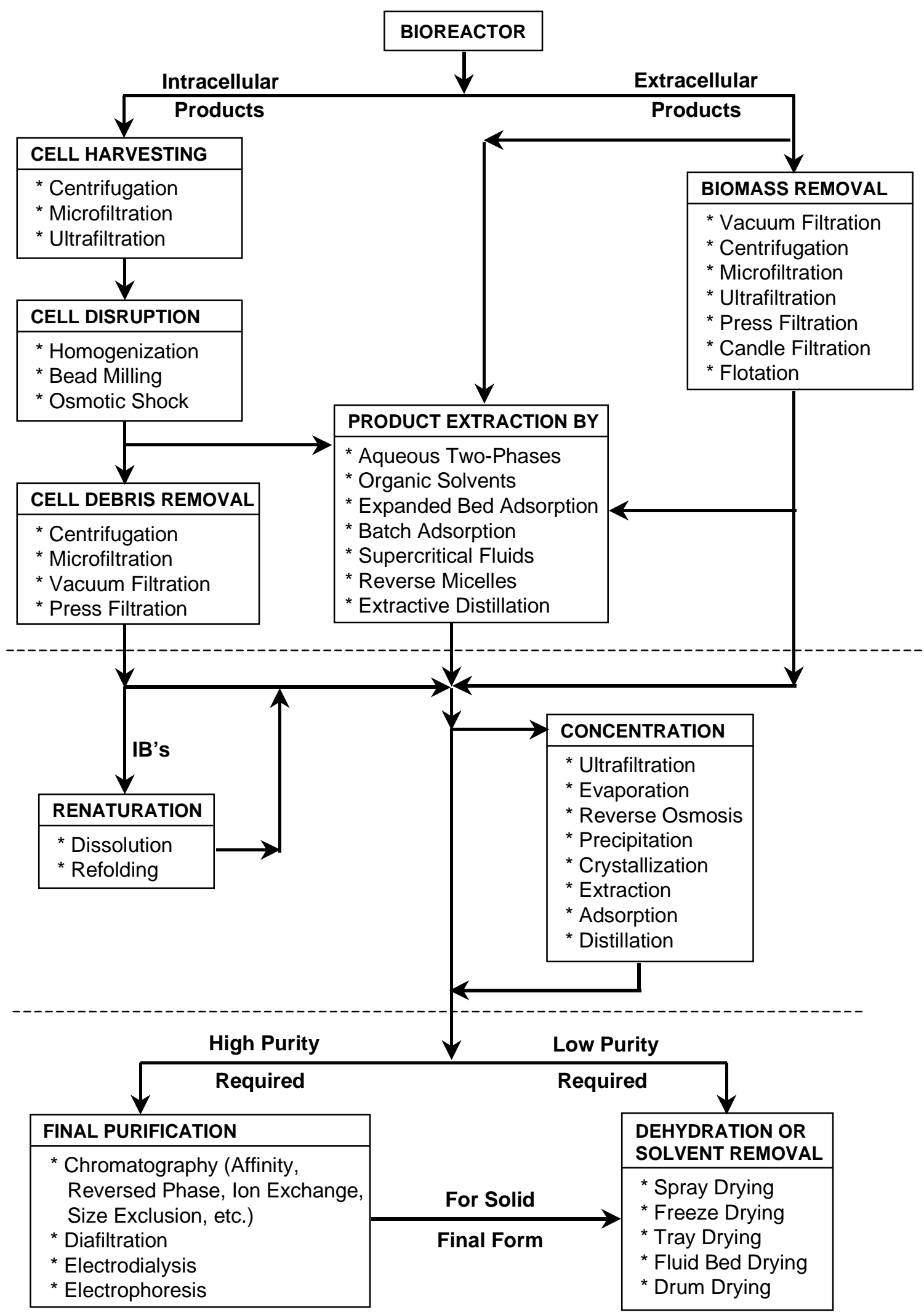

Figure 11-2 Generalized block diagram of downstream processing. 
Chapter 4, centrifugation has advantages for large and dense microorganims (diameter $>2 \mu \mathrm{m}$ and density $>1.03 \mathrm{~g} / \mathrm{cm}^{3}$ ). For instance, centrifugation is very efficient for harvesting yeast. For smaller microorganisms, various coagulation techniques can be used to increase the size of the settling particles (see Chapter 2). Membrane filtration has advantages for harvesting small and light cells. Another advantage of membrane filtration is in product recovery. Cell loss during centrifugation is typically 1 to $5 \%$. However, with membrane filtration, essentially all cells are recovered unless there is cell disruption (lysis) or ripped membranes.

Cell Disruption. This is usually the second step for intracellular products. Its purpose is to break open the host cells and release the intracellular product. The various options for cell disruption are presented in Chapter 2. Disruption of bacteria and yeast is carried out either by high pressure homogenizers or bead mills (Kula and Schutte, 1987). For large capacities (several $\mathrm{m}^{3} / \mathrm{h}$ ) only high pressure homogenizers are practical. Osmotic shock is often used for release of periplasmic products that accumulate between the cell membrane and the cell wall

Prior to disruption the concentrate is often diluted (by 5-10\%) with a "lysis buffer" to create conditions that minimize product denaturation upon release from the cell. For hard-to-disrupt microorganisms, multiple homogenizer passes at 500-1000 bar are required. Multiple passes are also required if the product forms inclusion bodies. This allows the inclusion bodies to be released, and also breaks the cell debris into very small particles, which facilitates the separation of inclusion bodies from cell debris further downstream. Some product protein degradation occurs during cell disruption due to high shear and oxidation.

Removal of Cell Debris. The cell debris that is generated by cell disruption is usually removed by centrifugation or microfiltration. Other options include rotary vacuum filtration, press filtration, depth filtration, extraction, and expanded bed adsorption (EBA) chromatography.

Soluble Product. When the product is soluble, it is recovered during cell debris removal either in the light phase of a centrifuge or in the permeate stream of a filter. Centrifuges efficiently separate only fairly large particles of cell debris (greater than $0.5 \mu \mathrm{m}$ Stokes' diameter). Therefore, when a centrifuge is used for cell debris removal, a polishing filtration step must follow to remove small debris particles which might otherwise cause severe problems in processes downstream such as chromatography. Various types of filters (e.g., depth, press, candle, rotary vacuum, membrane microfilters, etc.) can be used for polishing. Alternatively, these filters can be used for cell debris removal without a centrifugation step preceding them. It is very difficult to predict a priori which filter performs best for a specific product. When microfilters are used for cell debris removal, some degree of diafiltration is required to achieve an acceptable product recovery yield.

Insoluble Product. When the product is insoluble and forms inclusion bodies, it must first be separated from the cell debris particles, then dissolved and refolded (see the insulin example later in this chapter for a process of this type). Fortunately, inclusion bodies usually have a large diameter $(0.3-1.0 \mu \mathrm{m})$ and high density $\left(1.3-1.5 \mathrm{~g} / \mathrm{cm}^{3}\right)$ (Taylor et al., 1986) and can be separated from cell debris with a disk-stack centrifuge (Chapter 4). The inclusion bodies are 
recovered in the heavy phase of the centrifuge while most cell debris particles remain in the light phase. The heavy phase is usually resuspended and recentrifuged 2-3 times to reach a high degree of inclusion-body purity. Resuspension in a solution of a detergent and/or a low concentration of a chaotropic agent is often practiced to facilitate the removal of other contaminants. The $\mathrm{pH}$ and the ionic strength of the solution are adjusted to reduce the hydrophobicity of the cell debris particles and enhance their removal in the light phase. Final product purity exceeding $70 \%$ is quite common.

Product Extraction / Adsorption. Product separation from cell debris can also be carried out by extraction and/or adsorption. Organic solvents are commonly used as extractants for low molecular weight products, such as various antibiotics. Aqueous two-phase systems have found applications for recovery of proteins. The criteria for extractant selection are: the partition coefficient of the product should be higher than the partition coefficient of the contaminants; the extractant should not degrade the product; it should not be expensive; and it should be easy to recover or dispose of (see Chapter 5 for more detailed information on extraction).

In addition, product separation from debris and simultaneous concentration can be achieved by adsorptive techniques (Palmer, 1977). Various types of adsorbents (e.g., ion exchange, reverse phase, affinity, etc.) can be used. This type of purification requires the disrupted cells and product to be mixed in a stirred tank with an adsorbent. A washing step, where most of the cell debris particles and contaminants are washed out, follows product adsorption. More recently, expanded bed adsorption (EBA) chromatography has shown promise for separating proteins from cell debris particles (Chang and Chase, 1996). The feed is pumped upwards through an expanded bed. Target proteins are bound to the adsorbent while cell debris and other contaminants pass through. A washing step removes all weakly retained material. An elution step follows that releases and further purifies the product (see Chapter 6 for more detailed information on adsorption).

\section{EXTRACELLULAR PRODUCTS}

Biomass Removal. In agreement with the second generic heuristic, remove the easiest-toremove impurities first, biomass removal is usually the first step of downstream processing of extracellular products. This step can be accomplished by using one (or more) of the following unit operations: rotary vacuum filtration, disk-stack or decanter centrifugation, press filtration, microfiltration, ultrafiltration, flotation, etc. Since each unit operation has advantages and disadvantages for different products and microorganisms, the selection of the best unit operation(s) for a given system can be difficult.

Rotary vacuum filtration, especially with precoat, is the classical widely used method for removal of mycelial organisms (Dlouhy and Dahlstrom, 1968). Rotary vacuum filters can operate continuously for long periods of time (see Chapter 3). In addition, the filtrate flux in these units is usually higher than $200 \mathrm{~L} / \mathrm{m}^{2}-\mathrm{h}$ and may reach $1,000 \mathrm{~L} / \mathrm{m}^{2}-\mathrm{h}$. The most important disadvantage of this type of unit is the problem with the disposal of the mixture of filter-aid and biomass. Filter-aid is added in equal or higher amounts than biomass. Stringent environmental laws have 
made it costly to dispose of such solid materials. Therefore, if the disposal cost of filter aid is relatively high where a new plant is going to be built, alternative unit operations should be considered for biomass separation. However, if the disposal cost of filter aid is relatively low, a rotary vacuum filter is a good choice. The citric acid process, which is described later in this chapter, offers an example where rotary vacuum filtration is used for biomass removal.

Centrifugation. Disk-stack and decanter centrifuges are frequently used at large scale (Brunner and Hemfort, 1988; Axelson, 1985). Of the two, disk-stack centrifuges operate at higher rotational speeds and remove smaller and lighter microorganisms. However, with the use of coagulating agents, the decanter centrifuge performance improves, and choosing between the two types becomes more difficult. It appears that the only criterion being used to choose disk-stack as opposed to decanter is the ability to remove small, light microorganisms. Centrifugation does not require filter aid, which is a significant advantage compared to rotary vacuum filtration. In general, the centrifuge paste contains $40-60 \% \mathrm{v} / \mathrm{v}$ extracellular liquid. In order to recover the product dissolved in that liquid, the paste is usually washed and re-centrifuged.

Membrane filtration. With membrane filters (micro- and ultrafilters) the extracellular product passes through the membrane while biomass and other particulate components remain in the concentrate. Concentration is usually followed by diafiltration to increase the product recovery yield (see Chapter 3 for more information on the mode of operation of membrane filters). Membrane filters are used for biomass removal mainly in recovery of low molecular weight products, such as antibiotics from mycelia. For high molecular weight products, applications are limited to cases where the amount of solids is rather small as in cell culture.

\subsubsection{Intermediate Recovery Stages}

The primary recovery stages just described are followed by the intermediate stages, where the product is concentrated and further purified. If the product is soluble, product concentration is usually the first step. If the product is denatured and insoluble, first it is dissolved and refolded and then it is concentrated and purified.

Product Concentration. After primary separation, the product is usually in a dilute solution. Volume reduction by concentration is in agreement with heuristics 1 and 2. Common concentration options include ultrafiltration, reverse osmosis, evaporation, adsorption, precipitation, extraction, and distillation.

Ultrafiltration. is used extensively for protein solution concentration. The molecular weight cut-off of the membrane is selected to retain the product while allowing undesirable impurities (mainly low molecular weight solutes) to pass through the membrane. The low operating temperature and the purification achieved along with concentration are some of the advantages of ultrafiltration over evaporation. The typical operating trans-membrane pressure is $2-5$ bar and the average flux is $20-50 \mathrm{~L} / \mathrm{m}^{2}-\mathrm{h}$.

Reverse Osmosis filters employ membranes with smaller pore sizes and are used for concentrating medium to low molecular weight products (e.g., antibiotics, certain amino acids, etc.). 
Evaporation. Thin-film rotating evaporators can operate at relatively low temperatures (40$50{ }^{\circ} \mathrm{C}$ ) under vacuum. These units compete in the market with ultrafiltration and reverse osmosis for concentrating both low and high molecular weight compounds. One disadvantage of evaporation compared to ultrafiltration is the lack of any purification during concentration. Advantages include the ability to concentrate to a higher final solids concentration and the ability to handle large throughputs (Freese, 1983).

Precipitation is often used for concentration and purification. Blood protein fractionation (see Chapter 7.4) and citric acid production (see example later in this chapter) constitute typical applications. Addition of salts, solvents, and polymers and changes in $\mathrm{pH}$, ionic strength, and temperature are commonly used to selectively precipitate compounds of interest (Chan et al., 1986). Precipitation often follows an extraction carried out by a polymer/salt (e.g., PEG and potassium phosphate) aqueous two-phase system. When the product is recovered in the polymerrich phase, precipitation is accomplished by addition of more polymer. It is important for economic reasons to recover and recycle the precipitating materials. Precipitation is also used to remove contaminants, i.e. nucleic acids, by adding $\mathrm{MnSO}_{4}$ and streptomycin sulfate.

Distillation is used for concentrating and purifying organic solvents, such as ethanol, acetic acid, etc.

Product Renaturation. Eukaryotic proteins produced by prokaryotic microorganisms often form insoluble inclusion bodies (IB's) in the host cell. Inclusion bodies can be dissolved rapidly using solutions of strong chaotropes, such as $6 \mathrm{M}$ guanidine hydrochloride or urea, in the presence of a reducing agent, such as $0.5 \mathrm{M}$ 2-mercaptoethanol or $50 \mathrm{mM}$ dithiothrietol (Fish et al., 1985). The dissolved protein is then allowed to refold to its native conformation by removing the chaotropic agents through diafiltration or chromatography and diluting the solution down to total protein concentration of $20-50 \mathrm{mg} / \mathrm{L}$. Dilution is necessary for minimizing intermolecular interactions, which occur during product refolding and can lead to product inactivation. Addition of small amounts of reduced glutathione (2-5 mM) and oxidized glutathione (1-2 mM) and incubation at $35-40{ }^{\circ} \mathrm{C}$ for $5-10$ hours completes the refolding process. Thus, when choosing an upstream process that forms IB's consideration must be given to the large volumes, and hence large waste streams, that are produced. More information on IB solubilization and protein refolding can be found in the insulin example that is presented later in this chapter.

\subsubsection{Final Purification Stages}

The final purification steps are dependent on the required final product purity. Pharmaceutical products require high purity while industrial products require lower purity. For products of relatively low purity, such as detergent enzymes, the final purification step is dehydration or more generally a solvent removal step. For high purity products, the final purification stages usually involve a combination of chromatographic and filtration steps (Bjurstrom, 1985). If the final product is required in solid form, then, a dehydration or solvent removal step follows. 
Chromatography is typically done later in a process in agreement with the third generic heuristic, make the most difficult and expensive separations last. With the previous separation steps, a large fraction of contaminants is removed, thereby reducing the volume of material that needs to be treated further. In fact, a 50-100 fold volumetric reduction is quite common for highvalue biological products, resulting in a protein content of $1-5 \% \mathrm{w} / \mathrm{v}$ in the feed stream to chromatographic units.

Recent advances in expanded bed adsorption (EBA) chromatography promise to position chromatographic steps in the primary recovery stages (Chang and Chase, 1996). As mentioned earlier in this chapter (see Product Extraction / Adsorption), EBA chromatography units can be used to capture, concentrate, and purify product directly from fermentation broth that contains whole cells, cell debris and other particulate components. Consequently, EBA chromatography has the potential to eliminate some of the typical primary recovery steps, such as biomass and cell debris removal, product concentration, etc.

A sequence of chromatographic steps is usually required to achieve the desired final product purity, and the fourth and fifth generic heuristics are good guides for selecting and sequencing such steps (Wheelwright, 1987). For instance, according to the fifth heuristic, an ion exchange step should not be followed by another step of the same type. Instead, it should be followed by a reverse phase, affinity or any other chromatography step that takes advantage of a different separation driving force.

Membrane filtration steps are commonly employed between chromatographic steps to exchange buffers and concentrate the dilute product solutions. See Chapter 6 for detailed information on chromatographic separation methods and Chapter 3 for the intervening membrane filtration steps. The insulin and monoclonal antibody examples that are presented later in this chapter provide additional information on selection and operation of chromatographic separation units.

Dehydration or Solvent Removal is achieved with dryers. Spray, fluid bed, and tray dryers are used when products can withstand temperatures of $50-100{ }^{\circ} \mathrm{C}$. Freeze dryers are used for products that degrade at high temperatures. Freeze dryers require high capital expenditures and should be avoided if possible. See Chapter 9 for detailed information on product drying.

\subsection{PROCESS ANALYSIS}

The flowsheets put together during process synthesis must be analyzed and compared on the basis of capital investment, manufacturing cost, environmental impact, and other criteria in order to decide which ideas to consider further. Methodologies for estimating capital investment and manufacturing cost are presented in the next section of this chapter. The estimation of both is based on the results of material and energy balances and equipment sizing. Although these basic chemical engineering calculations can be done on paper, it is highly desirable to use more 
sophisticated computer aids, such as spreadsheets or process simulators. Use of computer tools allows the process design team to quickly and accurately redo the entire series of calculations for a different set of assumptions and other input data.

\subsubsection{Spreadsheets}

Spreadsheet applications, such as Microsoft Excel, Lotus 1-2-3, and Corel Quattro Pro have become as easy to use as word processors and graphics packages. In its simplest form, a spreadsheet is an electronic piece of paper with empty boxes, known as cells. The user can enter data in those cells, perform calculations, and generate results. Results from spreadsheets can be easily plotted in a variety of graphs.

\subsubsection{Process Simulators}

Process simulators are software tools that enable the user to readily represent and analyze integrated processes. They have been in use in the petrochemical industries since the early 1960's. Established simulators for the petrochemical industries include: Aspen Plus (from Aspen Technology, Inc.), ChemCAD (from Chemstations, Inc.), HYSYS (from Hyprotech, Ltd./AEA Engineering Software), and PRO/II (from Simulation Sciences, Inc.).

Development of simulators specific to biochemical processes began in the mid 1980's. BioProcess Simulator (BPS) (from Aspen Technology, Inc.) was the first tool of this type. For a given flowsheet, BPS used to carry out material and energy balances, estimate the size and cost of equipment, and perform economic evaluation. BPS has had limited commercial success because it was designed as an extension of Aspen Plus, an inherently steady-state simulator, and could not satisfactorily represent batch biochemical processes, which normally operate in batch mode.

BioPro Designer, the second product of this category, was initially developed at the Biotechnology Process Engineering Center (BPEC) of MIT. With a license to this technology, Intelligen, Inc. (Scotch Plains, NJ) completed the development of BioPro Designer and commercialized it, first for the Apple Macintosh and later for MS Windows. SuperPro Designer, an extension of BioPro, was created to address other related industries (e.g., synthetic pharmaceuticals, agrochemicals, food processes, etc.) as well as water purification and end-ofpipe treatment processes. SuperPro handles material and energy balances, equipment sizing and costing, economic evaluation, environmental impact assessment, process scheduling, and debottlenecking of batch and continuous processes.

Biotechnology Design Simulator (BDS), the third tool of this family, was developed by Life Sciences International (Philadelphia, PA). BDS runs on top of Gensym's G2 system and focuses on scheduling of batch operations and resource utilization as a function of time.

BATCHES from Batch Process Technologies (West Lafayette, IN) is a batch process simulator that has found applications in pharmaceuticals, biochemicals, and food processing. It is especially useful for fitting a new process into an existing facility and analyzing resource demand as a function of time. More recently, Aspen Technology and Hyprotech have introduced Batch 
Plus and BDK, respectively. Both mainly target synthetic pharmaceutical and specialty chemical processes, but it is expected that future versions of these tools will be able to handle biochemical processes as well.

Minimum requirements for a biochemical process simulator are the ability to handle batch as well as continuous processes and the ability to model the unit operations that are specific to bioprocessing. Due to its ability to satisfy these requirements, SuperPro Designer (from Intelligen, Inc.) will be used to illustrate the role of such tools in bioprocess design. A functional demonstration version of SuperPro Designer and additional information on bioprocess simulation can be obtained at http://wwwintelligen.com

To model an integrated process on the computer using a simulator, you must start by developing a flowsheet that represents the overall process. Figure 11-3, for instance, displays the flowsheet of a hypothetical process on the main window of SuperPro Designer. The flowsheet is developed by putting together the required unit operations (which will sometimes be referred to as "unit procedures", as will be explained later in this section) and joining them with material flow streams. Next, the user initializes the flowsheet by registering (selecting from the component database) the various materials that are used in the process and specifying operating conditions and performance parameters for the various operations.

Most biochemical processes operate in batch or semi-continuous mode. This is in contrast to continuous operation, which is typical in the petrochemical and other industries that handle large throughputs. In continuous operations, a piece of equipment performs the same action all the time (which is consistent with the notion of unit operations). In batch processing, on the other hand, a piece of equipment goes through a cycle of operations. For instance, a typical chromatography cycle includes equilibration, loading, washing, elution, and regeneration. In SuperPro Designer v4.0, the set of operations that comprise a processing step is called a "unit procedure" (as opposed to a "unit operation"). Each unit procedure contains individual tasks (e.g., equilibration, loading, etc.) called operations. A unit procedure is represented on the screen with a single equipment icon (for example, C-101 in Figure 11-3 represents the ion exchange chromatography procedure). In essence, a unit procedure is the recipe of a processing step that describes the sequence of actions required to complete that step. Figure 11-4 displays the dialog through which the recipe of a chromatography unit procedure is specified. On the left-hand side of that dialog, the program displays the operations that are available in a chromatography procedure; on the right-hand side, it displays the registered operations. The significance of the unit procedure is that it enables the user to describe and model the various activities of batch processing steps in detail. Later in this chapter (in the examples section) we will see how the execution of these activities can be visualized as a function of time.

For every operation within a unit procedure, SuperPro includes a mathematical model that performs material and energy balance calculations. Based on the material balances, SuperPro performs equipment-sizing calculations similar to some of the homework problems in the book. If multiple operations within a unit procedure dictate different sizes for a certain piece of equipment, the software reconciles the different demands and selects an equipment size that is 
appropriate for all operations. In other words, the equipment is sized so that it is large enough that it will not be overfilled during any operation, but it is no larger than necessary (in order to minimize capital costs). In addition, the software checks to ensure that the vessel contents will not fall below a user-specified minimum volume (e.g., a minimum stir volume) for applicable operations.

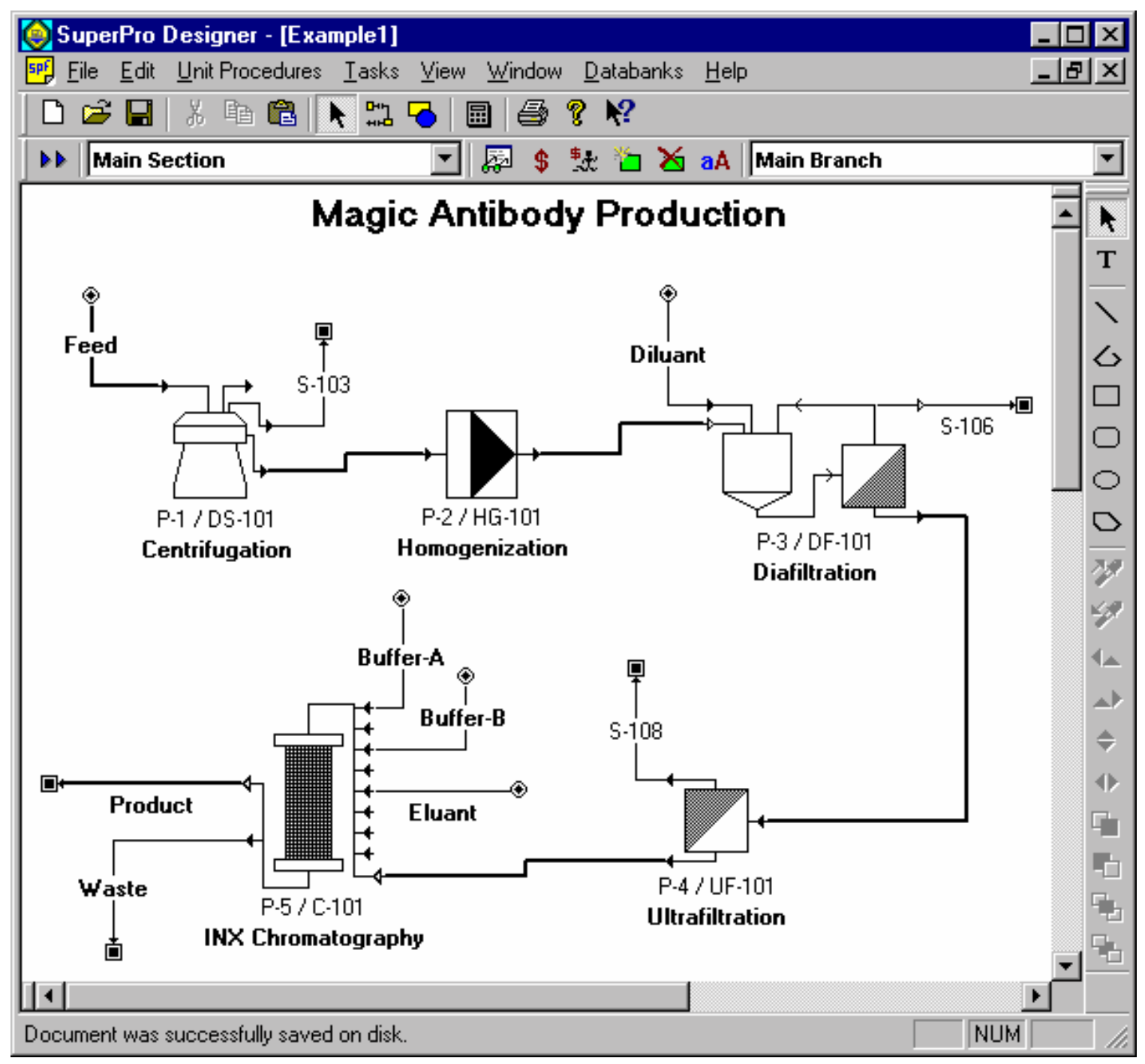

Figure 11-3 A flowsheet on the main window of SuperPro Designer.

Before any simulation calculations can be done, the user must initialize the various operations by specifying operating conditions and performance parameters through appropriate dialog windows. For instance, Figure 11-5 displays the initialization dialog of a chromatography elution operation. Through this dialog, the user specifies the elution strategy (isocratic or gradient), selects the buffer streams (two different solutions are required for gradient elution), identifies the component (Sodium Chloride in this case) whose concentration varies during 
elution, specifies its initial and final concentration, etc. Through the Labor, etc. tab of the same dialog window, the user provides information about labor requirement during this operation. Through the Scheduling tab one specifies the start time of this operation relative to the start or end time of another operation in the same procedure, or relative to an operation in another procedure. After initialization of the operations, the simulator performs material and energy balances for the entire process and estimates the required sizes of equipment. Optionally, the simulator may be used to carry out cost analysis and economic evaluation calculations. The fundamentals of process economics are described in the next section and pertinent examples are provided later in this chapter.

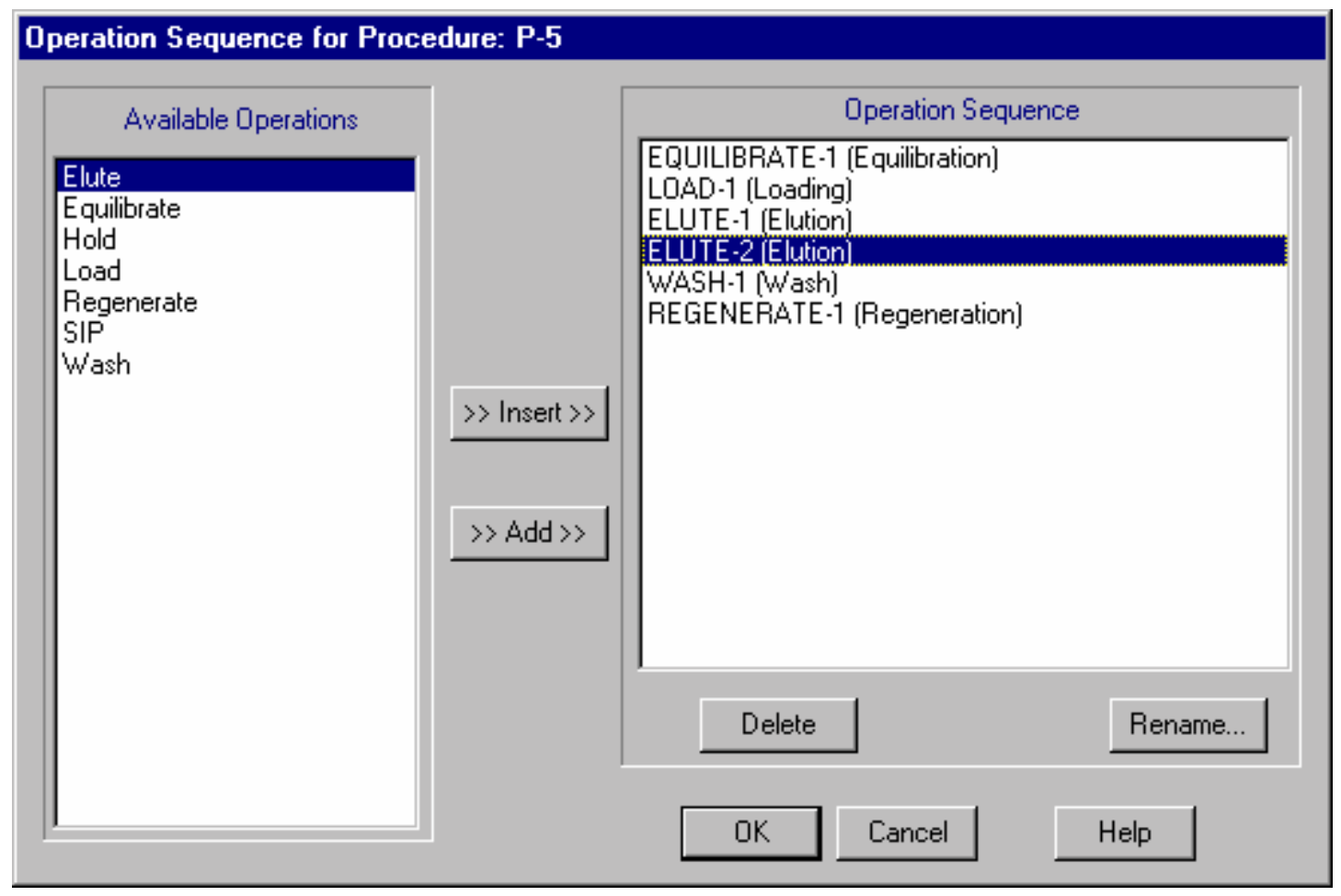

Figure 11-4 Window for adding operations to a unit procedure using SuperPro Designer.

Other tasks that can be handled by process simulators include process scheduling, environmental impact assessment, debottlenecking, and throughput analysis. Issues of process scheduling and environmental impact assessment will be addressed in the examples section. In throughput analysis and debottlenecking, the engineer analyzes the capacity and time utilization of equipment and resources (e.g., utilities, labor, raw materials) and tries to identify opportunities for increasing throughput with the minimum possible capital investment. Additional information on this subject can be found at http://wwwintelligen.com 


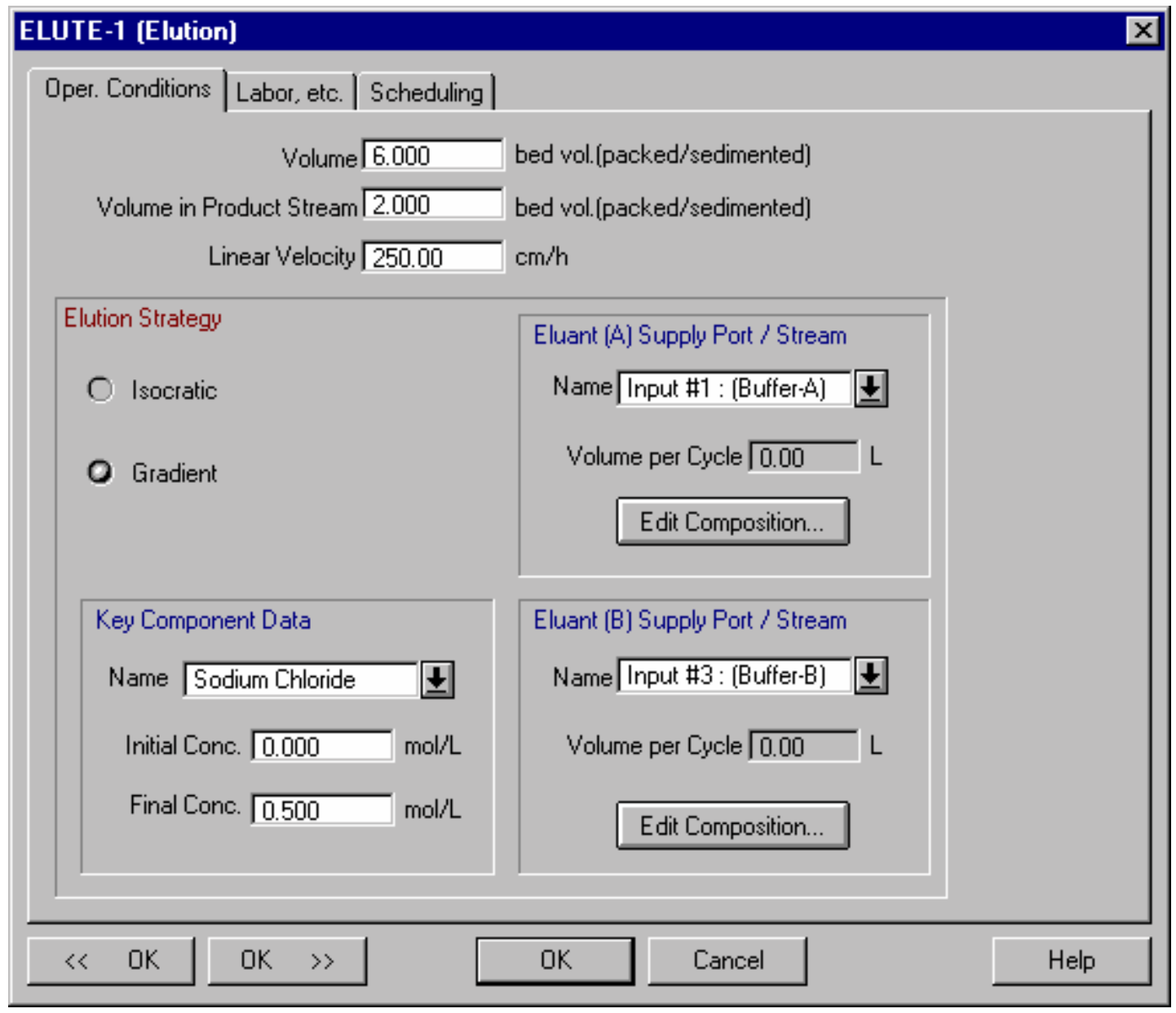

Figure 11-5 Dialog window of the elution operation.

Having developed a good model using a process simulator or a spreadsheet, the user may begin experimenting on the computer with alternative process setups and operating conditions. This has the potential of reducing the costly and time-consuming laboratory and pilot plant effort. Please be aware, however, that the GIGO (garbage-in, garbage-out) principle applies to all computer models. More specifically, if some of your assumptions and input data are incorrect, so will be the outcome of the simulation. Consequently, a certain validation of the model is necessary. In its simplest form, a review of the results by an experienced engineer can play the role of validation.

\subsection{PROCESS ECONOMICS}

The preliminary economic evaluation of a project for manufacturing a biological product usually involves the estimation of capital investment, estimation of operating costs, and analysis of profitability. For biopharmaceuticals, another figure worth considering is the average cost of new drug development, which is in the range of $\$ 200$ to $\$ 500$ million. This number is so high because it also includes research and development $(\mathrm{R} \& \mathrm{D})$ spending for all unsuccessful products. In other words, the actual average development cost per successful drug may be $\$ 20$ to $\$ 50$ million, but 
because more than $90 \%$ of new projects never reach commercialization, the average overall R\&D cost skyrockets to the above figures. This reinforces the need for effective process design tools and methodologies that assist engineers and scientists to efficiently evaluate and eliminate nonpromising project ideas at the very early stages of product and process development.

\subsubsection{Capital Cost Estimation}

The capital investment for a new plant includes three main items: 1) direct fixed capital (DFC), 2) working capital, and 3) startup and validation cost. The DFC for small biotechnology facilities is usually in the range of $\$ 30$ to 60 million, whereas for large facilities it is in the range of $\$ 100$ to 250 million. For preliminary design purposes, the various items of DFC are estimated based on the total equipment purchase cost (PC) using several multipliers. Table 11-2 provides ranges and average values for the multipliers and a skeleton for the calculations. Detailed definitions of the various cost items and additional information can be found in traditional process design textbooks and the technical literature (Peters and Timmerhaus, 1991; Ulrich, 1984; ValleRiestra, 1983; Garrett, 1989; Seider et al., 1999; Douglas, 1988).

Table 11-2 Fixed Capital Cost Estimation.

\begin{tabular}{|c|c|c|}
\hline COST ITEM & $\begin{array}{c}\text { Average } \\
\text { Multiplier }\end{array}$ & $\begin{array}{c}\text { Range } \\
\text { of values }\end{array}$ \\
\hline \multicolumn{3}{|c|}{ TOTAL PLANT DIRECT COST (TPDC) } \\
\hline \multicolumn{3}{|l|}{ 1. Equipment Purchase Cost (PC) } \\
\hline 2. Installation & $0.50 \times \mathrm{PC}$ & $0.2-1.5$ \\
\hline 3. Process Piping & $0.40 \times \mathrm{PC}$ & $0.3-0.6$ \\
\hline 4. Instrumentation & $0.35 \times \mathrm{PC}$ & $0.2-0.6$ \\
\hline 5. Insulation & $0.03 \times \mathrm{PC}$ & $0.01-0.05$ \\
\hline 6. Electrical & $0.15 \times \mathrm{PC}$ & $0.1-0.2$ \\
\hline 7. Buildings & $0.45 \times \mathrm{PC}$ & $0.1-2.0$ \\
\hline 8. Yard Improvement & $0.15 \times \mathrm{PC}$ & $0.05-0.2$ \\
\hline 9. Auxiliary Facilities & $0.50 \times \mathrm{PC}$ & $0.2-1.0$ \\
\hline \multicolumn{3}{|c|}{ TOTAL PLANT INDIRECT COST ( TPIC) } \\
\hline 10. Engineering & $0.25 \times \mathrm{TPDC}$ & $0.2-0.3$ \\
\hline 11. Construction & $0.35 \times \mathrm{TPDC}$ & $0.3-0.4$ \\
\hline TOTAL PLANT COST (TPC) & TPDC + TPIC & \\
\hline 12. Contractor's fee & $0.05 \times \mathrm{TPC}$ & $0.03-0.08$ \\
\hline 13. Contingency & $0.10 \times \mathrm{TPC}$ & $0.07-0.15$ \\
\hline DIRECT FIXED CAPITAL (DFC) & $\mathrm{TPC}+12+13$ & \\
\hline
\end{tabular}


Notice the wide range of multiplier values for estimating the cost of buildings. Plants for commodity biochemicals, such as ethanol and citric acid, fall on the low end of the range, whereas small biotech facilities that manufacture small amounts of high-value products fall on the high end. The average value of 0.45 corresponds to relatively large plants that produce medium to high value products. The insulin manufacturing facility that is analyzed later in this chapter falls under this category. For more accurate estimation of building costs, it is necessary to estimate the process area required based on the footprint of the equipment and the space required around the equipment for safe and efficient operation and maintenance. Then, the building cost is estimated by multiplying the area of the various sections (e.g., process, laboratory, office, etc.) of a plant by an appropriate unit cost provided in Table 11-3 (Frohlich, 1999). This table also provides information on air circulation rates for the various process areas, which determine the sizing and power requirements of heating, ventilation, and air conditioning (HVAC) systems.

Table 11-3 Building Cost Estimation.

\begin{tabular}{|c|c|c|}
\hline SPACE FUNCTION & $\begin{array}{c}\text { Unit Cost } \\
\$ / \mathbf{m}^{2}\end{array}$ & $\begin{array}{c}\text { Air Circulation Rates } \\
\text { (volume changes per hour) }\end{array}$ \\
\hline \multicolumn{3}{|l|}{ PROCESS AREAS* } \\
\hline Class 100,000 & $2,000-2,500$ & 20 \\
\hline Class 10,000 & $2,500-3,500$ & $35-50$ \\
\hline Class 1,000 & $4,500-6,000$ & 100 \\
\hline Class 100 & $6,000-8,000$ & $200-600$ \\
\hline MECHANICAL ROOM (Utilities) & $300-600$ & \\
\hline LABORATORY & $1000-2000$ & \\
\hline OFFICE & $500-600$ & \\
\hline
\end{tabular}

Source: BioMetics, Inc., Waltham, Massachusetts.

* The class number refers to the maximum number of particles $0.5 \mu \mathrm{m}$ or larger per cubic foot.

Referring back to Table 11-2, notice the wide range in the equipment installation cost multipliers. For higher accuracy, one should use multipliers that are specific to individual equipment items. In general, equipment delivered mounted on skids has a lower installation cost.

For preliminary cost estimates, Table 11-2 clearly shows that the fixed capital investment of a plant is a multiple (usually 5 to 8 times) of its equipment purchase cost. The equipment purchase cost can be estimated from vendor quotations, published data, company data compiled from previous projects, and by using process simulators and other computer aids. Vendor quotations are time-consuming to obtain and are therefore usually avoided for preliminary cost estimates. Instead, engineers tend to rely on the other three sources. Figures 11-6 to 11-9 provide literature data (in logarithmic format) for disk-stack centrifuges, high-pressure homogenizers, membrane filters, and chromatography columns. The data represent average values from several vendors. 
Oftentimes, cost data for one or two discrete equipment sizes is available, but the cost for a different size piece of equipment must be estimated. In such cases, the scaling law (expressed by the equation below) can be used:

$$
\operatorname{Cost}_{2}=\operatorname{Cost}_{1}\left(\frac{\text { Size }_{2}}{\text { Size }_{1}}\right)^{\mathrm{a}}
$$

The mathematical form of the scaling law explains why cost versus size data graphed on logarithmic coordinates tend to fall on a straight line. The value of the exponent (a) in the equation above ranges between 0.5 and 1.0 with an average value for vessels of around 0.6 (this explains why the scaling law is also known as the " 0.6 rule", which is just under $2 / 3$, the ratio of surface to volume for vessels). According to this rule, when the size of a vessel doubles, its cost will increase by a factor of $(2 / 1)^{0.6}$, or approximately $52 \%$. This is often referred to as the economy of scale. When using the scaling law, it is important to make sure that the piece of equipment whose cost is being estimated has a size that does not exceed the maximum available size for that type of equipment.

The price of equipment changes with time due to inflation and other market conditions. That change in price is captured by the Chemical Engineering Plant Cost Index (CE INDEX) that is published monthly by Chemical Engineering magazine. The index $I$ is used to update equipment cost data according to the following equation.

$$
\operatorname{Cost}_{2}=\operatorname{Cost}_{1}\left(\frac{I_{2}}{I_{1}}\right)
$$

Another factor that affects equipment purchase cost is the material of construction. As can be seen from Figure 11-9, a stainless steel chromatography column is more expensive than a plastic one of the same size. Similarly, a stainless steel tank costs 2.5 to 3 times as much as a carbon steel tank of the same size. Fortunately, in bioprocessing most of the equipment is made of stainless steel for GMP (good manufacturing practice) reasons, and selection of materials is less of a problem. Other factors that affect equipment cost include the finishing of the metal surface and the instrumentation that is provided with the equipment. This is the major cause for the wide range in prices for bioreactors.

Additional cost data for chemical processing equipment can be found in the literature (Peters and Timmerhaus, 1991; Ulrich, 1984; and Garrett, 1989). The choices are rather limited when it comes to cost data for bioprocessing equipment (Kalk and Langlykke, 1986 and Reisman, 1988). 


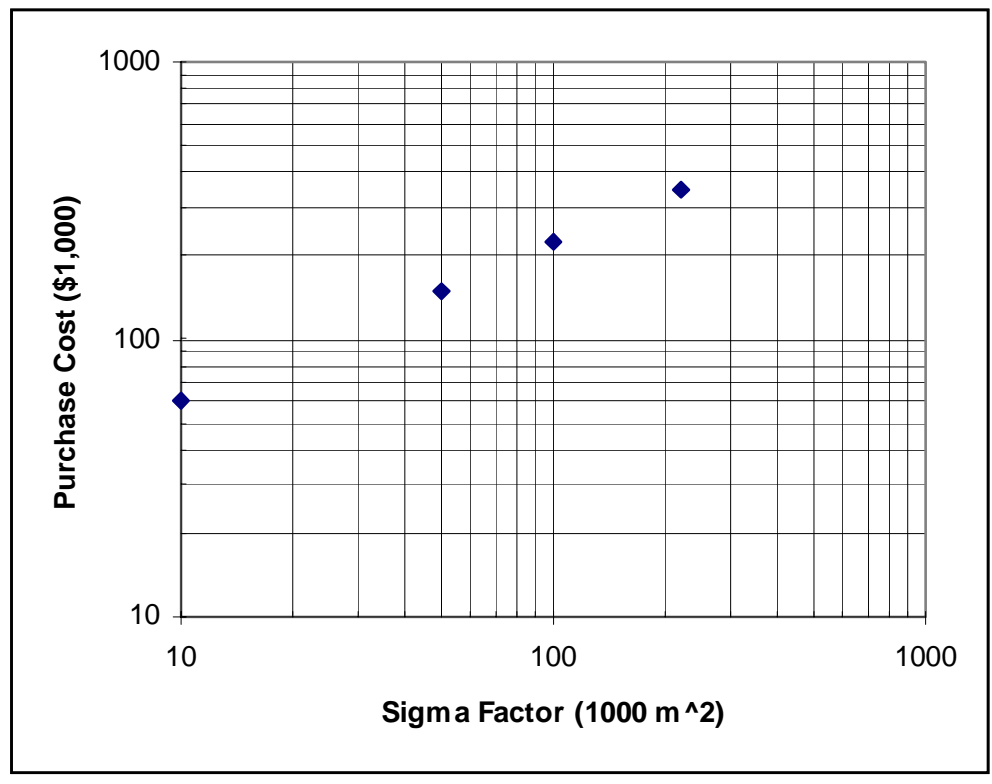

Figure 11-6 Purchase cost of disk-stack centrifuges vs. $\Sigma$ Factor (1998 prices).

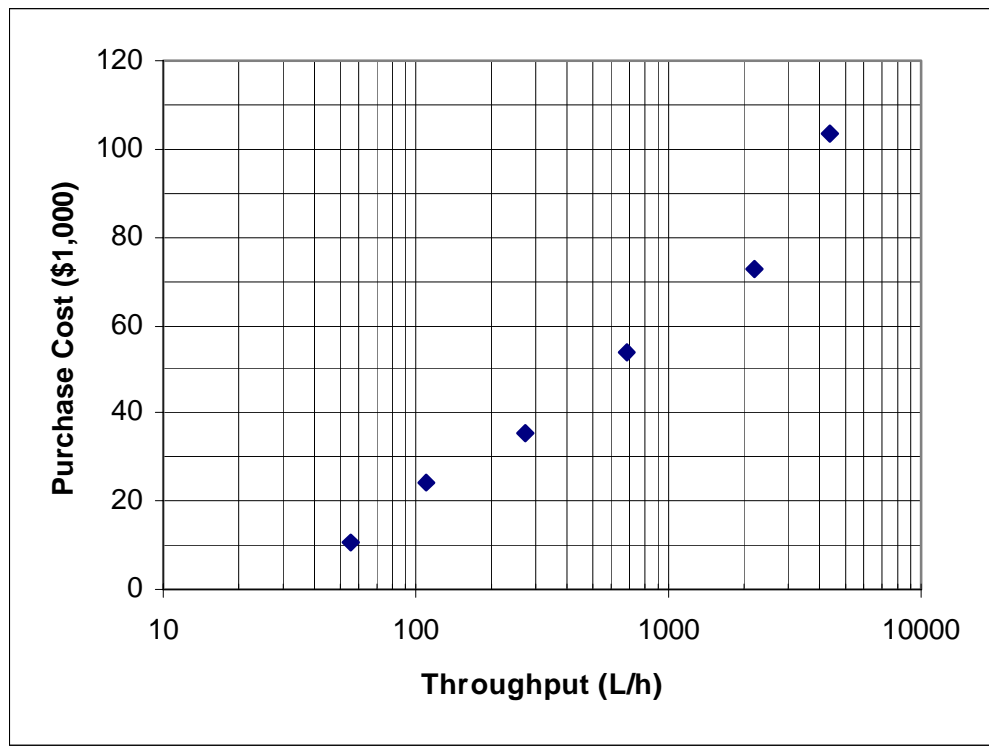

Figure 11-7 Purchase cost of high-pressure homogenizers vs. throughput (1998 prices). 


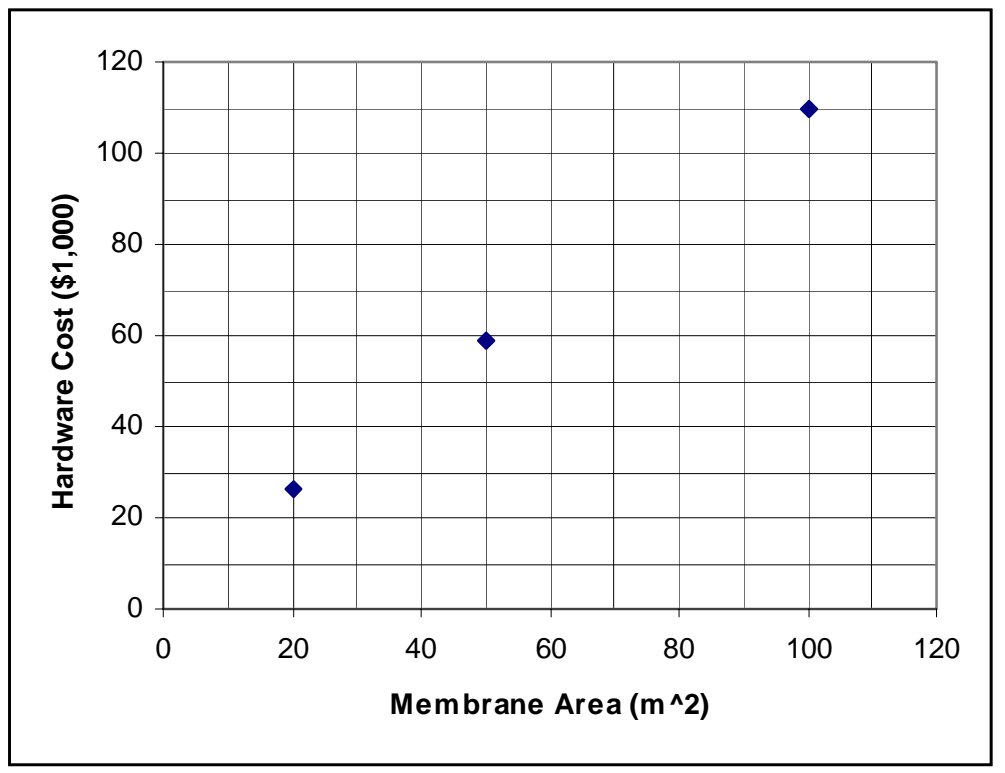

Figure 11-8 Purchase cost of MF/UF hardware (cost of membrane excluded).

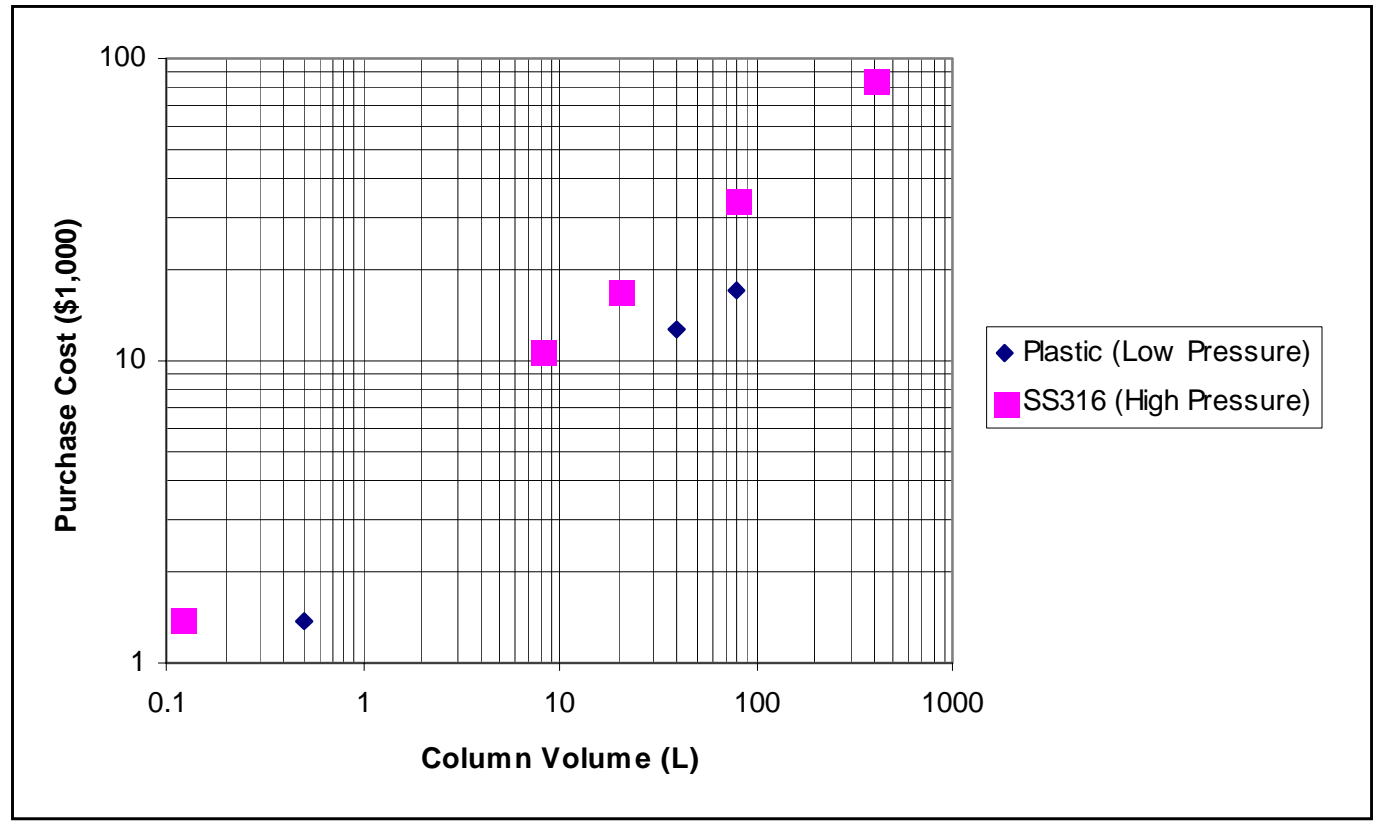

Figure 11-9 Purchase cost of chromatography columns made of plastic or stainless steel 316L for low- and high-pressue columns, respectively (1998 prices).

Table 11-4 Cost of chromatography column peripherals (pumps, controls, etc.)

\begin{tabular}{ccc}
\hline $\begin{array}{c}\text { Throughput } \\
(\mathbf{L} / \mathbf{m i n})\end{array}$ & $\begin{array}{c}\text { Low Pressure Column } \\
(\mathbf{\$})\end{array}$ & $\begin{array}{c}\text { High Pressure Column } \\
(\mathbf{\$})\end{array}$ \\
\hline $0.5-2.5$ & 95,000 & 160,000 \\
$2.5-5.0$ & 115,000 & 210,000 \\
$5.0-20.0$ & 125,000 & 260,000 \\
\hline
\end{tabular}


In addition to direct fixed capital costs, money must also be available to pay for the following items: 1) raw materials for 1-2 months, 2) labor for 2-3 months, 3) utilities for a month, 4) waste treatment/disposal for a month, and 5) other miscellaneous expenses. "Working capital" accounts for these investments in temporary expenses and consumable materials. The required amount of working capital for a process is usually 10 to $20 \%$ of the DFC.

Startup and validation costs can also represent a significant capital investment for a biopharmaceutical plant. A value of 5 to $10 \%$ of DFC is quite common.

\subsubsection{Operating Cost Estimation}

The operating cost to run a biochemical plant is the sum of all expenses associated with raw materials, labor, utilities, waste disposal, overhead, etc. Dividing the annual operating cost by the annual production rate yields the unit production cost (in $\$ / \mathrm{kg}$ ). Biotechnology is a unique industry when it comes to the range in unit production cost. There are products that cost less than $\$ 1.0 / \mathrm{kg}$ and others that cost more than $\$ 10,000,000 / \mathrm{kg}$ to make. The citric acid and therapeutic monoclonal antibody processes that are described in the examples section of this chapter lie close to these two extremes. If one also considers biological wastewater treatment with a unit cost of $\$ 0.1-0.5 / \mathrm{m}^{3}$ (or $\$ 0.0001 / \mathrm{kg}$ ), then, the range in order of magnitude in the unit processing cost is $10^{11}$.

Table 11-5 displays the various types of operating costs, their direct or indirect nature, and ranges for their values relative to the total operating cost. Sometimes cost items are categorized as either fixed or variable. Fixed costs are those that are incurred regardless of volume of product output. The clearest case of a fixed cost is depreciation, which is part of the equipment-dependent cost. The clearest case of a variable cost would be the cost of raw materials. Most other costs have a fixed and a variable component.

Table 11-5 Operating cost items and ranges.

\begin{tabular}{lcc}
\hline COST ITEM & $\begin{array}{c}\text { Type } \\
\text { Of Cost }\end{array}$ & $\begin{array}{c}\text { Range of values } \\
\text { (\% of total) }\end{array}$ \\
\hline A. Raw Materials & Direct & $10-80$ \\
B. Labor & Direct & $20-50$ \\
C. Consumables & Direct & $1-50$ \\
D. Lab/QC/QA & Direct & $2-50$ \\
E. Waste Disposal & Direct & $1-20$ \\
F. Utilities & Direct & $1-30$ \\
G. Equipment-Dependent & Indirect & $10-70$ \\
H. Miscellaneous & Indirect & $0-20$ \\
\hline
\end{tabular}


It is obvious from the wide range of values in Table 11.5 that one cannot estimate the operating cost of a product based on average values. A certain level of detailed calculations is required.

Table 11-6 Common bioprocessing raw materials (year 2000 prices), including materials used in fermentation (upstream processing)

\begin{tabular}{|c|c|c|}
\hline RAW MATERIAL & COMMENTS & PRICE (\$/kg) \\
\hline \multicolumn{3}{|l|}{ C-Source } \\
\hline Glucose & Solution $70 \% \mathrm{w} / \mathrm{v}$ & $0.25-0.35$ \\
\hline Corn Syrup & $95 \%$ Dextrose equivalent & $0.35-0.45$ \\
\hline Molasses & $50 \%$ Fermentable sugars & $0.08-0.12$ \\
\hline Soybean Oil & Refined & $0.80-0.90$ \\
\hline Corn Oil & Refined & $0.85-0.95$ \\
\hline Ethanol & USP Tax Free & $0.50-0.60$ \\
\hline Methanol & Gulf Coast & $0.20-0.25$ \\
\hline n-alkanes & & $0.35-0.50$ \\
\hline \multicolumn{3}{|l|}{ N-Source } \\
\hline Ammonia & Anhydrous, fert. grade & $0.20-0.25$ \\
\hline Soybean flour & $44 \%$ protein & $0.25-0.30$ \\
\hline Cottonseed flour & $62 \%$ protein & $0.45-0.55$ \\
\hline Casein & $13.5 \% \mathrm{w} / \mathrm{w}$ total $\mathrm{N}$ & $2.40-3.00$ \\
\hline Ammonium Sulfate & Technical & $0.15-0.25$ \\
\hline Ammonium Nitrate & Fert. grade $33.5 \% \mathrm{~N}$, bulk & $0.15-0.20$ \\
\hline Urea & $46 \% \mathrm{~N}$, agricultural grade & $0.20-0.25$ \\
\hline Yeast & Brewers, debittered & $2.60-3.20$ \\
\hline Whey & Dried, $4.5 \% \mathrm{w} / \mathrm{w} \mathrm{N}$ & $0.45-0.60$ \\
\hline \multicolumn{3}{|l|}{ Salts } \\
\hline $\mathrm{KH}_{2} \mathrm{PO}_{4}$ & USP, granular & $1.65-1.85$ \\
\hline $\mathrm{K}_{2} \mathrm{SO}_{4}$ & Granular, purified & $2.20-2.50$ \\
\hline $\mathrm{Na}_{2} \mathrm{HPO}_{4}$ & & $1.30-1.50$ \\
\hline $\mathrm{MgSO}_{4} \cdot 7 \mathrm{H}_{2} \mathrm{O}$ & & $0.25-0.35$ \\
\hline $\mathrm{ZnSO}_{4} \cdot 7 \mathrm{H}_{2} \mathrm{O}$ & Agricultural grade, powder & $0.50-0.60$ \\
\hline \multicolumn{3}{|l|}{ Other } \\
\hline City Water & & 0.0005 \\
\hline Distilled Water & & $0.01-0.05$ \\
\hline Water For Injection & & $0.05-0.2$ \\
\hline Ampicillin & & $250-300$ \\
\hline Penicillin & & $10-20$ \\
\hline Streptomycin & & $40-50$ \\
\hline
\end{tabular}

Raw Materials. This accounts for the cost of all fermentation media, recovery chemicals, and cleaning materials. For commodity biochemicals, such as ethanol, it is mainly the cost of fermentation media. For high value products, the buffers used for product recovery and equipment cleaning can be a major part of the materials cost. Table 11-6 provides a list of commonly used raw materials in the biochemical industries. Note that the price of a raw material can vary widely depending on its required purity. This can be clearly seen in the case of water. Water for injection (WFI), for instance, costs 100-500 times as much as city water. Prices of 
various raw materials can be found in the Chemical Marketing Reporter. More recently, a number of websites have come online where a buyer can find pricing information and request bids from suppliers.

Labor. This is estimated based on the total number of operators, which in turn is calculated by summing up the operator requirements of the various operations as a function of time. As will become clear in the examples later in this chapter, the labor requirement in a batch manufacturing facility varies with time. In a single product facility, the number of operators in each shift must be based on maximum demand during that shift. In multi-product facilities, each product line can employ a certain number of dedicated operators and utilize floating operators during periods of peak demand. In general, smaller facilities tend to utilize a larger number of operators per processing step because they are less automated. For instance, a small biotech company may utilize 2-3 operators to set up a fermentor, whereas in a large, highly automated fermentation facility a single operator may remotely handle the setup of six different fermentors from the control room. In general, a typical biotech company that deals with high-value products will allocate at least one operator to each processing step, such as centrifugation, membrane filtration, chromatography, etc. during its operation. The setup of a step may require multiple operators for a short period.

Consumables. This includes the cost of periodically replacing items that may be used up, fouled, or otherwise damaged during processing, such as membranes, chromatography resins, activated carbon, etc. As the examples later in this chapter will illustrate, the high unit cost of chromatography resins and their frequent replacement can make this item a major component of the operating cost.

Laboratory / QC / QA. This accounts for the cost of off-line analysis, quality control (QC), and quality assurance (QA) costs. Chemical and biochemical analysis and physical property characterization, from raw materials to final product, are a vital part of biochemical operations. This cost is usually $10-20 \%$ of the operating labor cost. However, for certain biopharmaceuticals that require a large number of very expensive assays, this cost can be as high as the operating labor. For such cases, it is important to account for the number and frequency of the various assays in detail. Changes in lot size that can reduce the frequency of analysis can have a major impact on the bottom line.

Waste Treatment / Disposal. This accounts for the treatment of wastewater and the disposal of solid and hazardous materials. The amount and composition of the various waste streams is derived from the material balances. Multiplying the amount by the appropriate unit cost yields the cost of treatment and disposal. Treatment of low biological oxygen demand (BOD) wastewater (less than $1,000 \mathrm{mg} / \mathrm{L}$ ) by a municipal wastewater treatment facility usually costs $\$ 0.2-0.5 / \mathrm{m}^{3}$. This is not a major expense for most biotech facilities that deal with high value products. Disposal, however, of contaminated solvents (generated by chromatography steps) and other regulated compounds can become a major expense because their unit disposal cost is in the range of $\$ 2-20 / \mathrm{kg}$ (usually higher that the purchase price of the same chemical). Waste disposal may 
also become a problem if an unwanted by-product is generated as part of the recovery chemistry of a process (see the citric acid example later in this chapter).

Utilities. This accounts for heating and cooling utilities as well as electricity. The amounts are calculated as part of the material and energy balances. Aerobic fermentors are major consumers of electricity but downstream processing equipment generally does not consume much electricity. In terms of unit cost, electricity costs around $\$ 0.1 / \mathrm{kWh}$, heating steam is around $\$ 4$ $8 / 1000 \mathrm{~kg}$, clean steam (generated utilizing purified water) is around $\$ 10-50 / 1000 \mathrm{~kg}$ (depending on the scale of production and level of water purity) and refrigerants around $\$ 0.05-0.1$ per 1,000 $\mathrm{kcal}$ of heat removed. In downstream processing, clean steam is mainly used for sterilizing equipment as part of equipment cleaning. Another common use is for sterilizing fermentation media. Note that purified water used for buffer preparation and equipment cleaning is often classified as a utility and not as a raw material, thus increasing the cost contribution of utilities.

Equipment-Dependent. This cost accounts for the depreciation of the fixed capital investment, maintenance of equipment, insurance, local (property) taxes and possibly other overhead-type expenses. For preliminary cost estimates, the entire fixed capital investment is usually depreciated linearly over a 10-year period. In the real world, the government allows corporations to depreciate equipment in 5-7 years and buildings in 25-30. Land is never depreciated. The annual equipment maintenance cost can be estimated as a percentage of the equipment's purchase cost (usually 10\%). Insurance rates depend to a considerable extent upon the maintenance of a safe plant in good repair condition. A value for insurance in the range of $0.5-1 \%$ of DFC is appropriate for most bioprocessing facilities. The processing of flammable, explosive, or dangerously toxic materials usually results in higher insurance rates. The local (property) tax is usually 2-5\% of DFC. The factory expense represents overhead cost incurred by the operation of non-process-oriented facilities and organizations, such as accounting, payroll, fire protection, security, cafeteria, etc. A value of 5-10\% of DFC is appropriate for these costs.

Miscellaneous. This accounts for on-going R\&D, process validation and other overheadtype expenses. Expenses of this type can be ignored in preliminary cost estimates.

Other general expenses of a corporation include royalties, advertising, and selling. If any part of the process or any equipment used in the process is covered by a patent not assigned to the corporation undertaking the new project, permission to use the teachings of the patent must be negotiated, and some form of royalties is usually required. Advertising and selling covers expenses associated with the activities of the sales department.

\subsubsection{Profitability Analysis}

With estimates of capital investment, operating cost, and revenues of a project, one can proceed to assess its profitability and attractiveness from an investment point of view. There are various measures for assessing profitability. The simplest ones include gross margin, return on investment (ROI), and payback time and they are calculated using the following equations: 
Gross Margin $=\frac{\text { Gross Profit }}{\text { Revenues }}$

Return on Investment $($ ROI $)=\frac{\text { Net Profit }}{\text { Total Investment }} \times 100 \%$

Payback Time (in years) $=\frac{\text { Total Investment }}{\text { Net Profit }}$

where gross profit is equal to annual revenues minus the annual operating cost and net profit is equal to gross profit minus income taxes plus depreciation. All variables are averaged over the lifetime of a project.

Other measures that are more involved, such as the net-present-value (NPV) and internal-rate-ofreturn (IRR) consider the cash flows of a project over its evaluation life and the value of money as a function of time. Detailed definitions for NPV and IRR can be found in the literature (Peters and Timmerhaus, 1991). The examples that are presented later in this chapter demonstrate how these measures facilitate the decision making process.

\subsection{ILLUSTRATIVE EXAMPLES}

The use of SuperPro Designer is illustrated to analyze and evaluate the production of three biological products. The first example analyzes the production of citric acid, a commodity organic acid. The second deals with the production of recombinant human insulin, the first commercial product of modern biotechnology. The third example focuses on the production of monoclonal antibodies (MAb's) using mammalian cells cultured in stirred-tank bioreactors. The generation of the flowsheets for the production of all three products was based on information available in the patent and technical literature combined with our engineering judgment and experience with other biological products. We use these flowsheets to draw general conclusions on the manufacturing cost of biological products. The computer files for these examples are available as part of the demonstration version of SuperPro at htp//wwwintelligen com

\subsubsection{Citric Acid Production}

A number of organic acids are produced via fermentation. Of these, citric acid is produced in the largest amount (more than 400,000 metric tons per year). Citric acid is marketed as citric acid-1-hydrate or as anhydrous citric acid. The majority of citric acid (more than 60\%) is used in the food and beverage industries to preserve and enhance flavor. In the chemical industries (25-30\% of total), citric acid is used for the treatment of textiles, as a softener, as an antifoam agent, etc. In the pharmaceutical industry (10\% of total), iron citrate is used as a source of iron and citric acid is used as a preservative for stored blood, tablets, ointments, and in 


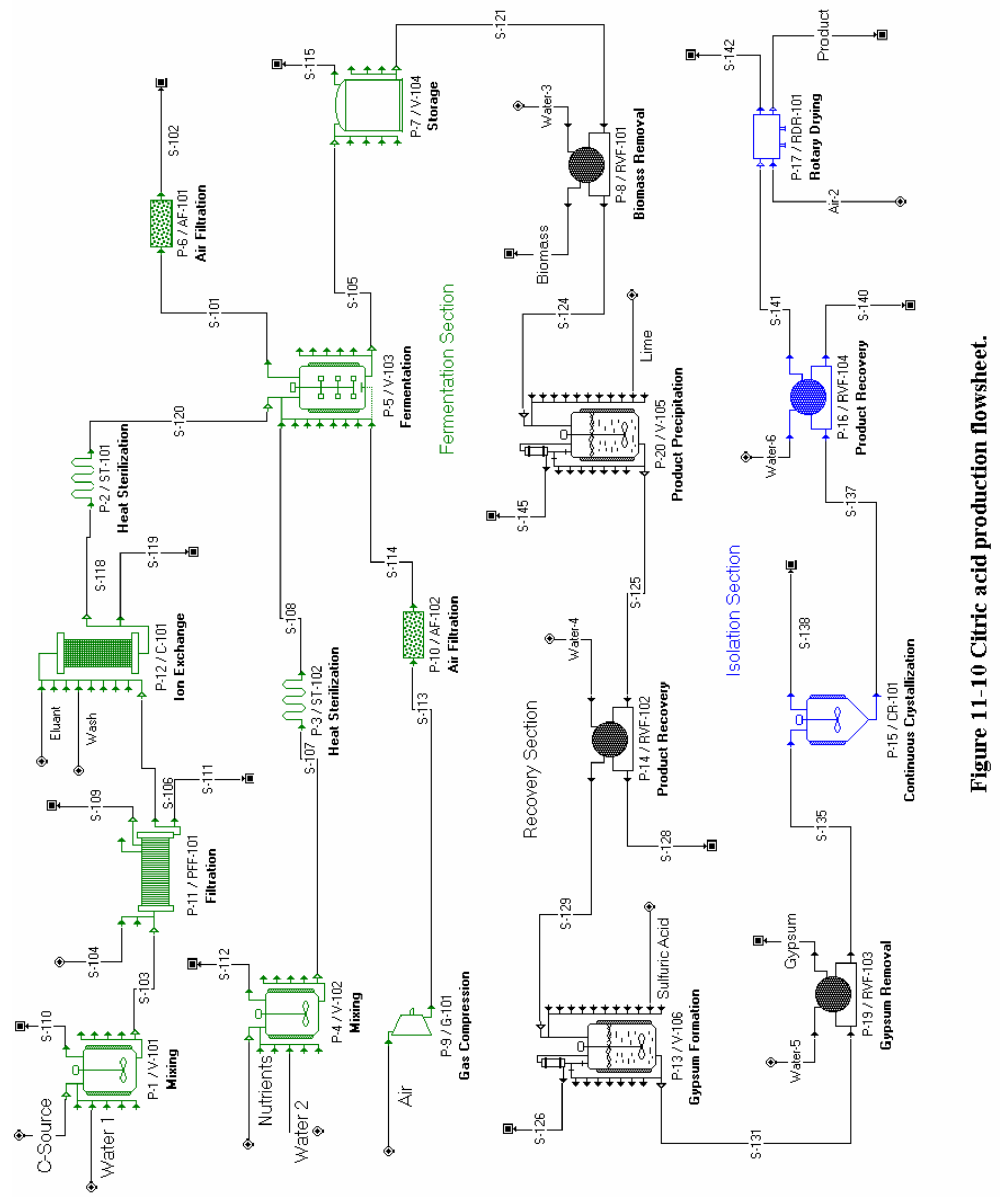


cosmetic preparations (Crueger and Crueger, 1989). Citric acid is being used more and more in the detergent industry as a replacement for polyphosphates.

Citric acid was first recovered in 1869 in England from calcium citrate, which was obtained from lemon juice. Its production by filamentous fungi has been known since 1893 . The first production via surface culture fermentation was initiated in 1923. Production using stirredtank fermentors began in the 1930's and it is presently the preferred method for large scale manufacturing. The plant analyzed in this example produces around 10,000,000 kg of crystal citric acid per year, which represents approximately $2.5 \%$ of the current world demand.

\section{Process Description}

Upstream section. The entire flowsheet is shown in Figure 11-10. Molasses, the carbon source of fermentation, is diluted from about $50 \%$ fermentable sugars content to $20 \%$ with water in a blending tank (V-101). Suspended particulate material is removed by filtration (PFF-101). Metal ions, particularly iron, are removed by an ion-exchange chromatography column (C-101). The purified raw material solution is then heat-sterilized (ST-101). Nutrients (i.e., sources of ammonium, potassium, phosphorous, magnesium, copper, and zinc) are dissolved in water (V102) and heat-sterilized (ST-102).

The fermentation cycle is 7 days and the production is handled by 7 fermentors that operate in staggered mode. Since the plant operates around the clock, one fermentation cycle is initiated daily and another one is completed daily. Each fermentor has a vessel volume of $260 \mathrm{~m}^{3}$ and handles broth of around $207.4 \mathrm{~m}^{3}$. Each production fermentor (V-103) is preceded by two smaller seed fermentors, which are not shown in the flowsheet. A pure culture of the mold Aspergillus niger is used to inoculate the smallest seed fermentor. When optimum growth of mycelium is reached, the contents of the seed fermentor are transferred to the next stage fermentor, which is approximately ten times larger. Similarly, this larger seed fermentor inoculates the production fermentor with about $10 \%$ volume of actively growing mycelium broth. Air is supplied by a compressor (G-101) at a rate that gradually increases from 0.15 to $1.0 \mathrm{VVM}$ (volume of air per volume of liquid per minute). Cooling water removes the heat produced by the exothermic process $\left(2,990 \mathrm{kcal} / \mathrm{kg}\right.$ of citric acid formed) and maintains the temperature at $28{ }^{\circ} \mathrm{C}$. The fermented broth is discharged into the holding tank (V-104), which acts as a buffer tank between the batch upstream section and the continuous downstream section.

Dowstream section. Purification starts with the removal of biomass by a rotary vacuum filter (RVF-101). The clarified fermentation liquor flows to an agitated reaction vessel (V-105). Approximately 1 part of hydrated lime, $\mathrm{Ca}(\mathrm{OH})_{2}$, for every 2 parts of liquor is slowly added to precipitate calcium citrate. The lime solution must be very low in magnesium content if losses due to the relatively soluble magnesium citrate are to be avoided. Calcium citrate is separated by a second rotary vacuum filter (RVF-102) and the citrate-free filtrate (S-128) is disposed of. The calcium citrate cake is sent to another agitated reaction vessel $(\mathrm{V}-106)$ where it is acidified with 
dilute sulfuric acid to form a precipitate of calcium sulfate (gypsum). A third filter (RVF-103) removes the precipitated gypsum and yields an impure citric acid solution. Careful control of $\mathrm{pH}$

and temperature of the precipitation steps is important for maximizing the yield of citric acid. The resulting solution is concentrated and crystallized using a continuous evaporator / crystallizer (CR-101). The crystals formed are separated by filtration (RVF-104) and dried in a rotary dryer (RDR-101). If the final product is required in high purity, treatment with activated carbon may precede crystallization to remove colorants. Ion exchange is sometimes used to remove metal ions and other ionic species.

\section{Material balances}

Table 11-7 provides a summary of the overall material balances. "CA Crystal" stands for crystalline citric acid and represents the final product. Glucose represents the fermentable carbohydrates in molasses $\left(50 \%\right.$ w/w). Note the large amounts of $\mathrm{Ca}(\mathrm{OH})_{2}$ and sulfuric acid consumed and gypsum (calcium sulfate) generated. Their quantities depend on the chemistry of the recovery process and cannot be reduced without changing the recovery technology. Since this gypsum is contaminated with biomass, it has little or no commercial value. A disposal cost of $\$ 50 /$ ton (metric) was assumed in this example. The large amount of wastewater is also worth noting.

Table 11-7 Overall material balances (kg/year).

\begin{tabular}{lrrr}
\hline COMPONENT & IN & OUT & (OUT-IN) \\
\hline Amm. Sulfate & 156,000 & 13,000 & $-143,000$ \\
Biomass & 0 & $1,033,000$ & $1,033,000$ \\
CA Crystal & 0 & $10,124,000$ & $10,124,000$ \\
Ca(OH)2 & $6,767,000$ & 580,000 & $-6,187,000$ \\
Calcium Citrate & 0 & 346,000 & 346,000 \\
CO2 & 0 & $1,848,000$ & $1,848,000$ \\
Citric Acid & 0 & 365,000 & 365,000 \\
Glucose & $12,741,000$ & 138,000 & $-12,603,000$ \\
Gypsum & 0 & $11,087,000$ & $11,087,000$ \\
Impurities & 127,000 & 127,000 & 0 \\
Nutrients & 936,000 & 95,000 & $-841,000$ \\
Oxygen & $19,062,000$ & $15,152,000$ & $-3,910,000$ \\
NaOH & 75,000 & 75,000 & 0 \\
Sulfuric Acid & $8,396,000$ & 407,000 & $-7,989,000$ \\
Water & $166,088,000$ & $172,958,000$ & $6,870,000$ \\
TOTAL & $\mathbf{2 1 4 , 3 4 8 , 0 0 0}$ & $\mathbf{2 1 4 , 3 4 8 , 0 1 9}$ & $\mathbf{0}$ \\
\hline
\end{tabular}




\section{Economic evaluation}

Table 11-8 provides a list of major equipment items along with their purchase costs (generated by SuperPro Designer). The total equipment cost for a plant of this capacity is around $\$ 12$ million. Note that more than $50 \%$ of the equipment cost is

Table 11-8 Major equipment specification and purchase costs (year 2000 prices in USD).

\begin{tabular}{|c|c|c|c|c|}
\hline Quantity & Name & Description & Unit Cost (\$) & Cost (\$) \\
\hline 4 & V-101 & $\begin{array}{l}\text { Blending Tank } \\
\text { Volume }=80 \mathrm{~m}^{\wedge} 3\end{array}$ & 116,000 & 464,000 \\
\hline 1 & ST-101 & $\begin{array}{l}\text { Heat Sterilizer } \\
\text { Throughput }=18 \mathrm{~m}^{\wedge} 3 / \mathrm{h}\end{array}$ & 353,000 & 353,000 \\
\hline 1 & ST-102 & $\begin{array}{l}\text { Heat Sterilizer } \\
\text { Throughput }=4 \mathrm{~m}^{\wedge} 3 / \mathrm{h}\end{array}$ & 220,000 & 220,000 \\
\hline 1 & $V-102$ & $\begin{array}{l}\text { Blending Tank } \\
\text { Volume }=80 \mathrm{~m}^{\wedge} 3\end{array}$ & 116,000 & 116,000 \\
\hline 1 & C-101 & $\begin{array}{l}\text { Ion Exchange Column } \\
\text { Volume }=2.1 \mathrm{~m}^{\wedge} 3\end{array}$ & 305,000 & 305,000 \\
\hline 1 & PFF-101 & $\begin{array}{l}\text { Plate \& Frame Filter } \\
\text { Filter Area }=80 \mathrm{~m}^{\wedge} 2\end{array}$ & 155,000 & 155,000 \\
\hline 1 & AF-102 & $\begin{array}{l}\text { Air Filter } \\
\text { Throughput }=0.13 \mathrm{~m}^{\wedge} 3 / \mathrm{s}\end{array}$ & 4,000 & 4,000 \\
\hline 1 & AF-101 & $\begin{array}{l}\text { Air Filter } \\
\text { Throughput }=0.68 \mathrm{~m}^{\wedge} 3 / \mathrm{s}\end{array}$ & 8,000 & 8,000 \\
\hline 1 & G-101 & $\begin{array}{l}\text { CF Compressor } \\
\text { Power }=226.29 \mathrm{~kW}\end{array}$ & 174,000 & 174,000 \\
\hline 7 & $V-103$ & $\begin{array}{l}\text { Fermentor } \\
\text { Volume }=260 \mathrm{~m}^{\wedge} 3\end{array}$ & 950,000 & $6,650,000$ \\
\hline 3 & $V-104$ & $\begin{array}{l}\text { Flat Bottom Tank } \\
\text { Volume }=300 \mathrm{~m}^{\wedge} 3\end{array}$ & 102,000 & 306,000 \\
\hline 1 & RVF-101 & $\begin{array}{l}\text { Rotary Vacuum Filter } \\
\text { Filter Area }=35.22 \mathrm{~m}^{\wedge} 2\end{array}$ & 87,000 & 87,000 \\
\hline 1 & $V-105$ & $\begin{array}{l}\text { Stirred Jacket Vessel } \\
\text { Volume }=3.8 \mathrm{~m}^{\wedge} 3\end{array}$ & 99,000 & 99,000 \\
\hline 1 & RVF-102 & $\begin{array}{l}\text { Rotary Vacuum Filter } \\
\text { Filter Area }=80 \mathrm{~m}^{\wedge} 2\end{array}$ & 132,000 & 132,000 \\
\hline 1 & V-106 & $\begin{array}{l}\text { Stirred Jacket Vessel } \\
\text { Volume }=5 \mathrm{~m}^{\wedge} 3\end{array}$ & 103,000 & 103,000 \\
\hline 1 & RVF-103 & $\begin{array}{l}\text { Rotary Vacuum Filter } \\
\text { Filter Area }=52 \mathrm{~m}^{\wedge} 2\end{array}$ & 102,000 & 102,000 \\
\hline 1 & CR-101 & $\begin{array}{l}\text { Crystallizer } \\
\text { Volume }=19 \mathrm{~m}^{\wedge} 3\end{array}$ & 122,000 & 122,000 \\
\hline 1 & RVF-104 & $\begin{array}{l}\text { Rotary Vacuum Filter } \\
\text { Filter Area }=25.5 \mathrm{~m}^{\wedge} 2\end{array}$ & 76,000 & 76,000 \\
\hline 1 & RDR-101 & $\begin{array}{l}\text { Rotary Dryer } \\
\text { Area }=8.5 \mathrm{~m}^{\wedge} 2 \\
\text { Cost of Unlisted Equipment }\end{array}$ & 101,000 & $\begin{array}{r}101,000 \\
2,394,000\end{array}$ \\
\hline TOTAL & & & & $11,970,000$ \\
\hline
\end{tabular}

associated with the seven production fermentors. The fermentors are made of stainless steel to minimize leaching of heavy metals that affect product formation. The "Cost of 
Unlisted Equipment" accounts for the cost of the seed fermentors and other secondary equipment that is not considered explicitly. Table 11-9 displays the various items of the direct fixed capital (DFC) investment. The total DFC for a plant of this capacity is around $\$ 56.5$ million or approximately 4.7 times the total equipment cost.

Table 11-9 Fixed capital estimate summary (year 2000 prices in USD).

\begin{tabular}{lrr}
\hline A. TOTAL PLANT DIRECT COST (TPDC) & \\
1. Equipment Purchase Cost & $11,970,000$ & \\
2. Installation & $4,015,000$ & \\
3. Process Piping & $4,190,000$ & $3,591,000$ \\
4. Instrumentation & 359,000 & \\
5. Insulation & $1,197,000$ & \\
6. Electricals & $2,394,000$ & \\
7. Buildings & $1,796,000$ & \\
8. Yard Improvement & $1,197,000$ & \multirow{2}{*}{$30,708,000$} \\
9. Auxiliary Facilities & & \\
$\quad$ TPDC = & & \\
B. TOTAL PLANT INDIRECT COST (TPIC) & $7,677,000$ & \\
10. Engineering & $10,748,000$ & \\
11. Construction & & $49,133,000$ \\
$\quad$ TPIC = & & \\
C. TOTAL PLANT COST (TPC = TPDC+TPIC) & $2,457,000$ & \\
12. Contractor's fee & $4,913,000$ & \\
13. Contingency & $7,370,000$ & \\
$\quad(12+13)=$ & $56,503,000$ & \\
D. DIRECT FIXED CAPITAL (DFC) TPC+12+13 & \\
\hline
\end{tabular}

Table 11-10 provides a summary of the operating cost. The equipment-dependent cost is the most important item, accounting for $49 \%$ of the overall operating cost. Depreciation of the fixed capital investment and maintenance of the facility are the main contributors to this cost. Raw materials account for around $18 \%$ of the overall cost. Molasses is the most expensive raw material, accounting for $82 \%$ of the raw materials cost. The following prices were assumed: $\$ 0.1 / \mathrm{kg}$ of molasses, $\$ 0.01 / \mathrm{kg}$ of $10 \% \mathrm{w} / \mathrm{w} \mathrm{H}_{2} \mathrm{SO}_{4}$ solution, $\$ 0.05 / \mathrm{kg}$ of $\mathrm{Ca}(\mathrm{OH})_{2}$, and $\$ 0.5 / \mathrm{m}^{3}$ of process water. Utilities are the third largest expense, accounting for $13.5 \%$ of the overall cost. Electricity and chilled water utilized by the fermentors are the main contributors to this cost. Labor lies in the fourth position and the environmental cost (waste treatment/disposal) is fifth. Disposal unit costs of $\$ 1 / \mathrm{m}^{3}$ and $\$ 50 / 1000 \mathrm{~kg}$ were assumed for liquid and solid (gypsum and biomass) waste streams, respectively.

The overall unit production cost is approximately $\$ 2.2 / \mathrm{kg}$. This is above the current selling price of citric acid. This can be explained by the excess capacity around the world and the fact that most operating citric acid plants are rather old and partially depreciated. If depreciation is ignored, the equipment-dependent cost is reduced by more than $80 \%$ and the overall unit cost drops to around $\$ 1.3$, which is slightly below the selling price of citric acid. 
Table 11-10 Operating cost summary (year 2000 prices).

\begin{tabular}{lrrr}
\hline Cost Item & $\mathbf{\$} \mathbf{k g ~ M P}$ & $\mathbf{\$} /$ Year & $\%$ \\
\hline Raw Materials & 0.40 & $3,949,000$ & 17.79 \\
Equipment & 1.09 & $10,866,000$ & 48.96 \\
Labor & 0.27 & $2,668,000$ & 12.02 \\
Consumables & 0.00 & 19,000 & 0.09 \\
Lab/QC/QA & 0.04 & 400,000 & 1.80 \\
Waste Trtm/Disp & 0.13 & $1,290,000$ & 5.81 \\
Utilities & 0.30 & $3,003,000$ & 13.53 \\
Total & $\mathbf{2 . 2 2}$ & $\mathbf{2 2 , 1 9 5 , 0 0 0}$ & $\mathbf{1 0 0 . 0 0}$ \\
\hline
\end{tabular}

$\mathrm{MP}=$ Main Product $=$ CA Crystal

Based on the preliminary evaluation of this project idea, one should not recommend investing in citric acid production unless there is a combination of favorable conditions.

Obviously, availability of inexpensive equipment (e.g., by acquiring an existing facility) and raw materials (by locating the plant near a source of cheap molasses) are the most important factors. Development or adoption of a superior technology may also change the attractiveness of citric acid production. Such a technology is actually available and utilizes extraction for citric acid recovery (Roberts, 1979). Recovery by extraction eliminates the consumption of $\mathrm{Ca}(\mathrm{OH})_{2}$ and $\mathrm{H}_{2} \mathrm{SO}_{4}$ and the generation of the unwanted $\mathrm{CaSO}_{4}$. Butanol has been used as an extractant, as has tri-butyl phosphate. Ion pair extraction, using secondary or tertiary amines dissolved in a waterimmiscible solvent (e.g., octyl alcohol), provides an alternative route. With recent developments in electrodialysis membranes, the use of this technique to recover citric acid directly from the fermentation broth may become an attractive alternative (Blanch and Clark, 1997). The analysis of an extraction-based process is available as part of the examples that are distributed with the demonstration version of SuperPro Designer.

\subsubsection{Human Insulin Production}

\section{Introduction}

Insulin facilitates the metabolism of carbohydrates and is essential for the supply of energy to the cells of the body. Impaired insulin production leads to the disease diabetes mellitus, which is the third largest cause of death in industrialized countries after cardiovascular diseases and cancer (Barfoed, 1987).

Human insulin is a polypeptide consisting of 51 amino acids arranged in two chains: A with 21 amino acids, and $\mathrm{B}$ consisting of 30 amino acids. The A and $\mathrm{B}$ chains are connected by two disulfide bonds. Human insulin has a molecular weight of 5,734 and an isoelectric point of 5.4. Human insulin can be produced by four different methods:

- Extraction from human pancreas.

- Chemical synthesis via individual amino acids. 
- Conversion of pork insulin or "semisynthesis."

- Fermentation of genetically engineered microorganisms.

Extraction from the human pancreas cannot be practiced due to the limited availability of raw material. Total synthesis, while technically feasible, is not economically viable due to the very low yield. Production based on pork insulin, also known as "semisynthesis," transforms the porcine insulin (which differs only in one amino acid) molecule into an exact replica of the human insulin molecule by substituting the amino acid threonine for alanine in the G-30 position. This technology has been developed and implemented by Novo Nordisk A/S (Denmark). However, this option is also quite expensive because it requires the collection and processing of large amounts of porcine pancreases. In addition, its supply is limited by the availability of porcine pancreas.

At least three alternative technologies have been developed for producing human insulin based on fermentation and utilizing recombinant DNA technology (Ladisch and Kohlmann, 1992).

Two-chain method. This was the first successful technique of biosynthetic human insulin (BHI) production based on recombinant DNA technology. This technique was developed by Genentech, Inc. (South San Francisco, CA) and scaled-up by Eli Lilly and Co. (Indianapolis, IN). Each insulin chain is produced as a $\beta$-galactosidase fusion protein in Escherichia coli forming inclusion bodies. The two peptide chains are recovered from the inclusion bodies, purified, and combined to yield human insulin. Later, the $\beta$-galactosidase operon was replaced with the tryptophan (Trp) operon, resulting in a substantial yield increase.

Proinsulin method (intracellular). This method eliminates the need for two different fermentation and purification trains that the previous option requires. In this case, intact proinsulin is produced instead of the separate A and B chains. The proinsulin route has been commercialized by Eli Lilly and Co. (Kehoe, 1989). Figure 11-11 shows the key transformation steps. The E. coli cells overproduce Trp-LE'-Met-proinsulin in the form of inclusion bodies, which are recovered and solubilized. Proinsulin is released by cleaving the methionine linker using $\mathrm{CNBr}$. The proinsulin chain is subjected to a folding process to allow intermolecular disulfide bonds to form, and the $\mathrm{C}$ peptide is then cleaved with enzymes to yield human insulin. A number of chromatography and membrane filtration steps are utilized to purify the product.

Proinsulin method (secreted). Novo Nordisk A/S has developed a technology based on yeast cells that secrete insulin as a single-chain insulin precursor (Barfoed, 1987). Secretion simplifies product isolation and purification. The precursor contains the correct disulfide bridges and is therefore identical to those of insulin. It is converted to human insulin by transpeptidation in organic solvent in the presence of a threonine ester and trypsin followed by de-esterification. Another advantage of this technology is the ability to reuse the cells by employing a continuous bioreactor-cell separator loop.

In this example, we analyze a process based on the intracellular proinsulin method, which has been commercialized by Eli Lilly and Co. 


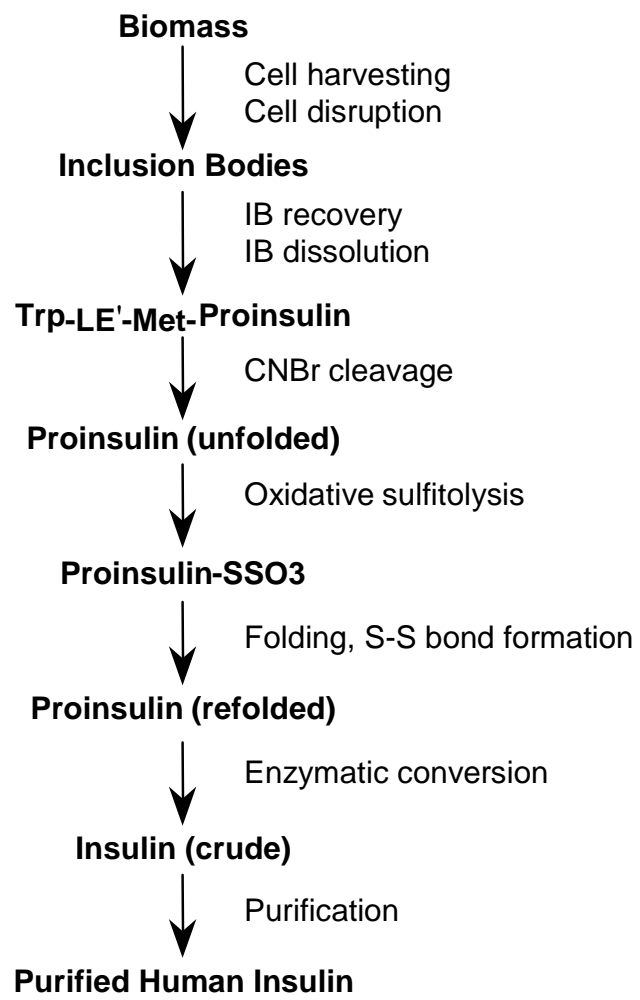

Figure 11-11 Human insulin from proinsulin fusion protein.

\section{Market Analysis and Design Basis}

The current world demand for insulin is in the range of 15,000 to $25,000 \mathrm{~kg}$ per year and it is growing at an annual rate of 5\% to 6\% (Datar and Rosen, 1990; Petrides et al., 1995). The plant analyzed in this example has a capacity of around $1,800 \mathrm{~kg}$ of purified biosynthetic human insulin (BHI) per year. This is a relatively large plant for producing polypeptide-based biopharmaceuticals. The plant operates around the clock for 330 days a year. A new batch is initiated every 48 hours resulting in 160 batches per year. The fermentation broth volume per batch is approximately $37.5 \mathrm{~m}^{3}$.

\section{Process Description}

The entire flowsheet for the production of BHI is shown in Figure 11-12. It is divided into four sections: 1) Fermentation, 2) Primary Recovery, 3) Reactions, and 4) Final Purification. Note - a "section" in SuperPro is simply a set of unit procedures (processing steps). If you open the computer file ("insulin.spf") using SuperPro, you will see that the unit procedures in each section have their own distinctive color (blue, green, purple, and black for Fermentation, Primary Recovery, Reactions, and Final Purification, respectively). 


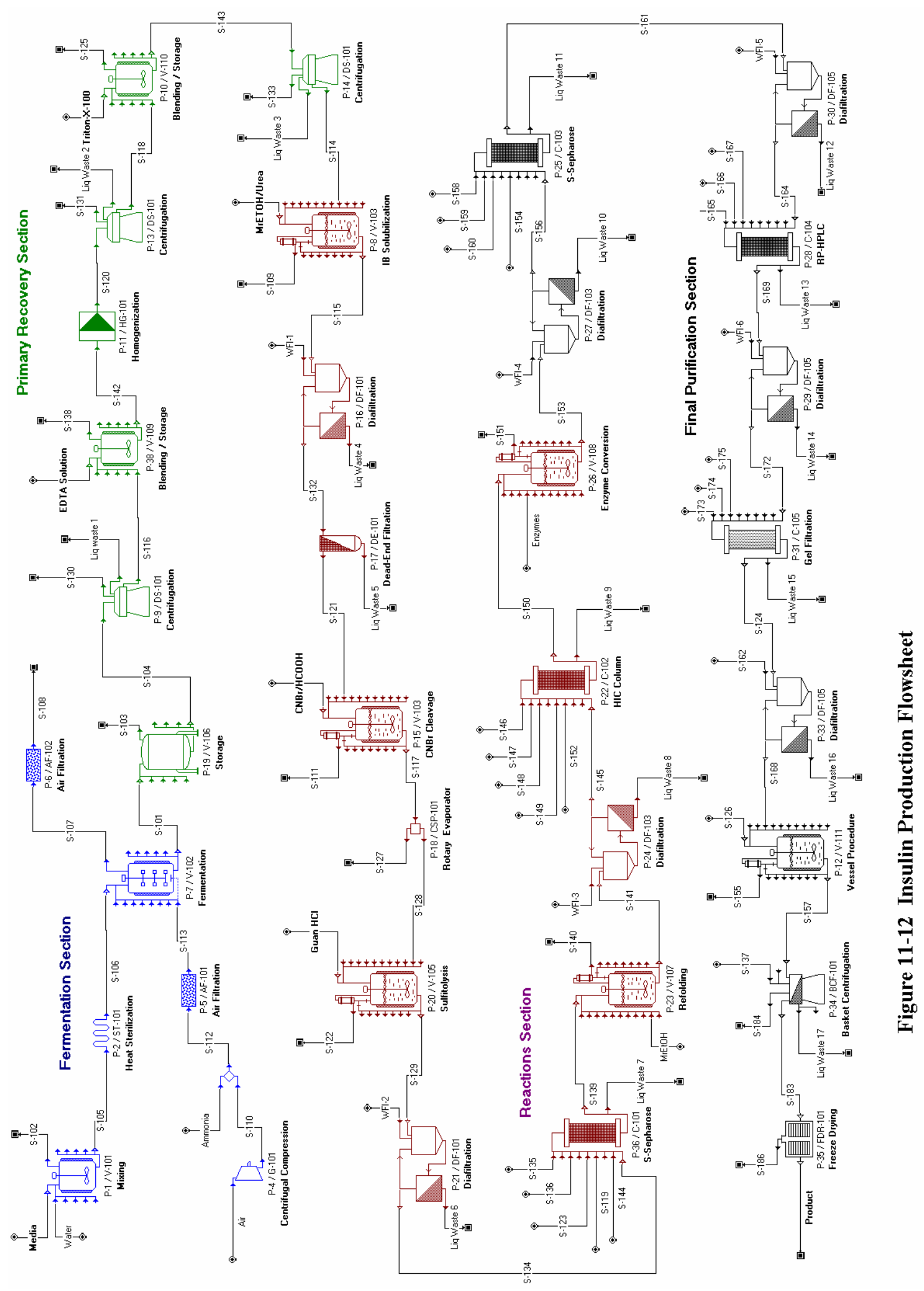




\section{Fermentation Section}

Fermentation media are prepared in a stainless steel tank (V-101) and sterilized in a continuous heat sterilizer (ST-101). The axial compressor (G-101) and the absolute filter (AF101) provide sterile air and ammonia to the fermentor at an average rate of 0.5 VVM. A two-step seed fermentor train (not shown in the flowsheet) is used to inoculate the $50 \mathrm{~m}^{3}$ production fermentor (V-102) with transformed E. coli cells. These cells are used to produce the Trp-LE'MET-proinsulin precursor of insulin, which is retained in the cellular biomass. The fermentation time in the production fermentor is about 18 hours, and the fermentation temperature is $37{ }^{\circ} \mathrm{C}$. The final concentration of $E$. coli in the production fermentor is about $30 \mathrm{~g} /$ liter (dry cell weight). The Trp operon is turned on when the $E$. coli fermentation runs out of tryptophan. The chimeric protein Trp-LE'-MET-proinsulin accumulates intracellularly as insoluble aggregates (inclusion bodies) and this decreases the rate at which the protein is degraded by proteolytic enzymes. In the base case, it was assumed that the inclusion bodies (IB's) constitute $20 \%$ of total dry cell mass. At the end of fermentation, the broth is cooled down to $10{ }^{\circ} \mathrm{C}$ to minimize cell lysis. After completing each processing step in the Fermentation Section (and subsequent sections), the equipment is washed in order to prepare for the next batch of product.

\section{Primary Recovery Section}

After the end of fermentation, the broth is transferred into a surge tank (V-106) which isolates the upstream from the downstream section of the plant. Three disk stack centrifuges (DS101) operating in parallel are used for cell harvesting. Please note that a single unit procedure icon on the screen of SuperPro may represent multiple equipment items operating in parallel (to see the number of equipment items a particular icon represents, right-click on the icon, go to Equipment Data, and look at the "Number of Units" field on the Equipment tab). During centrifugation, the broth is concentrated from $37,000 \mathrm{~L}$ to $9,165 \mathrm{~L}$, and most of the extracellular impurities are removed. The cell recovery yield is $98 \%$. The cell sludge is diluted with an equal volume of buffer solution (buffer composition: $96.4 \% \mathrm{w} / \mathrm{w}$ WFI (water for injection), $0.7 \%$ EDTA, and 2.9\% TRIS-Base ) using a blending tank (V-109). The buffer facilitates the separation of the cell debris particles from inclusion bodies. Next, a high pressure homogenizer (HG-101) is used to break the cells and release the inclusion bodies. The broth undergoes three passes under a pressure drop of 800 bar. The exit temperature is maintained at around $10^{\circ} \mathrm{C}$. The same centrifuges as before (DS-101) are then used for inclusion body recovery (P-13). The reuse of these centrifuges can be seen by the fact that procedures P-9 and P-13 have the same equipment name, DS-101. The IB's are recovered in the heavy phase (with a yield of 98\%) while most of the cell debris particles remain in the light phase. This is possible because the density $\left(1.3 \mathrm{~g} / \mathrm{cm}^{3}\right)$ and 
size (diameter ca. 1 micron) of the IB's are significantly greater than that of the cell debris particles. The IB sludge, which contains approximately $20 \%$ solids w/w, is washed with WFI containing $0.66 \% \mathrm{w} / \mathrm{w}$ Triton-X-100 detergent (the volume of solution is 2 times the volume of inclusion body sludge) and recentrifuged (P-14) using the same centrifuges as before (DS-101). The detergent solution facilitates purification (dissociation of debris and soluble proteins from inclusion bodies). The exit temperature is maintained at $10^{\circ} \mathrm{C}$. The slurry volume at the end of the primary recovery section is around $1,400 \mathrm{~L}$.

\section{Reactions Section}

Inclusion Body Solubilization. The inclusion body suspension is transferred to a glasslined reaction tank (V-103) and is mixed with urea and 2-mercaptoethanol to final concentrations of $300 \mathrm{~g} / \mathrm{L}(5 \mathrm{M})$ and $40 \mathrm{~g} / \mathrm{L}$, respectively. Urea is a chaotropic agent that dissolves the denatured protein in the inclusion bodies and 2-mercaptoethanol is a reductant that reduces disulfide bonds. A reaction time of 8 hours is required to reach a solubilization yield of $95 \%$. The inclusion bodies are composed of $80 \%$ w/w Trp-LE'-Met-proinsulin, with the remainder being other (contaminant) proteins. After the end of the solubilization reaction, urea and 2-mercaptoethanol are replaced with WFI and the solution is concentrated using a diafiltration unit (DF-101). This operation is performed in 6 hours with a recovery yield of $98 \%$. All remaining fine particles (biomass, debris, and inclusion bodies) are removed using a polishing dead-end filter (DE-101). This polishing filter protects the chromatographic units that are used further downstream. The solution volume at this point is around $5,200 \mathrm{~L}$.

$\mathrm{CNBr}$ cleavage. The chimeric protein is cleaved with $\mathrm{CNBr}$ (cyanogen bromide) into the signal sequence Trp-LE'-Met, which contains 121 amino acids, and the denatured proinsulin (82 amino acids) in the same reactor (V-103) that was used for IB solubilization. The reaction is carried out in a $70 \%$ formic acid solution containing 30-fold molar excess $\mathrm{CNBr}$ (stoichiometrically, one mole of $\mathrm{CNBr}$ is required per mole of Trp-LE'-Met-proinsulin). The reaction takes 12 hours at $20^{\circ} \mathrm{C}$ and reaches a yield of $95 \%$. The mass of the released proinsulin is approximately $30 \%$ of the mass of Trp-LE'-Met-proinsulin. A small amount of cyanide gas is formed as a by-product of the cleavage reaction. Detailed information on $\mathrm{CNBr}$ cleavage is available in the patent literature (U.S. Patent No. 4,451,396, 1984.). The formic acid, unreacted $\mathrm{CNBr}$, and generated cyanide gas are removed by applying vacuum and raising the temperature to around $35^{\circ} \mathrm{C}$ (the boiling point of $\mathrm{CNBr}$ ). This operation is carried out in a rotary vacuum evaporator (CSP-101) and takes 1 hour. Since cyanide gas is toxic, all air exhausted from the vessels is scrubbed with a solution of hypochlorite, which is prepared and maintained in situ (Kehoe, 1989).

Sulfitolysis. Sulfitolysis of the denatured proinsulin takes place in a reaction tank (V-105) under alkaline conditions ( $\mathrm{pH}$ 9-11). This operation is designed to unfold proinsulin, break any disulfide bonds, and add $\mathrm{SO}_{3}$ moieties to all sulfur residues on the cysteines. The product of 
interest is human proinsulin( $\left(\mathrm{S}_{-} \mathrm{SO}_{3}{ }^{-}\right)_{6}$ (protein-S-sulfonate). The sulfitolysis step is necessary for two reasons: (1) the proinsulin is probably not folded in the correct configuration when expressed in E. coli as part of a fusion protein, and (2) the cyanogen bromide treatment tends to break existing disulfide bonds. The final sulfitolysis mixture contains $50 \% \mathrm{w} / \mathrm{w}$ guanidine $\cdot \mathrm{HCl}(6 \mathrm{M})$, $0.35 \%$ ammonium bicarbonate $\left(\mathrm{NH}_{4} \mathrm{HCO}_{3}\right), 3 \% \mathrm{Na}_{2} \mathrm{SO}_{3}$ and $1.5 \% \mathrm{Na}_{2} \mathrm{O}_{6} \mathrm{~S}_{4}$ (U.S. Patent No. $4,923,967,1990)$. A reaction time of 12 hours is required to reach a yield of $95 \%$. The presence of the denaturing reagent (guanidine $\bullet \mathrm{HCl}$ ) prevents refolding and cross-folding of the same protein molecule onto itself or two separate protein molecules onto each other. Urea may also be used as a denaturing reagent. After the completion of the sulfitolysis reaction, the sulfitolysis solution is exchanged with WFI to a final guanidine $\bullet \mathrm{HCl}$ concentration of $20 \% \mathrm{w} / \mathrm{w}$. This procedure, P-21, utilizes the DF-101 diafilter that also handles buffer exchange after IB solubilization. The human proinsulin $\left(\mathrm{S}_{-} \mathrm{SO}_{3}\right)_{6}$ is then chromatographically purified using three ion-exchange columns (C-101) operating in parallel. Each column has a diameter of $140 \mathrm{~cm}$ and a bed height of $25 \mathrm{~cm}$. A cation exchange resin is used (SP Sepharose Fast Flow from AmershamPharmacia Biotech) operating at $\mathrm{pH}$ 4.0. The eluant solution contains: $69.5 \% \mathrm{w} / \mathrm{w}$ WFI, $29 \%$ urea, and $1.5 \% \mathrm{NaCl}$. Urea, a denaturing agent, is used to prevent incorrect refolding and crossfolding of proinsulin $\left(\mathrm{S}_{-} \mathrm{SO}_{3}-\right)_{6}$. The following operating assumptions were made: (1) the column is equilibrated for 30 minutes prior to loading, (2) the total resin binding capacity is $20 \mathrm{mg} / \mathrm{ml}$, (3) the eluant volume is equal to 5 column volumes (CV's), (4) the total volume of the solutions for column wash, regeneration and storage is 15 CV's, and (5) the protein of interest is recovered in 1.5 CV's of eluant buffer with a recovery yield of $90 \%$.

Refolding. This operation catalyzes the removal of the SO3 moiety and then allows disulfide bond formation and correct refolding of the proinsulin to its native form. It takes place in a reaction tank (V-107). This process step involves treatment with mercaptoethanol, a reductant that facilitates the disulfide interchange reaction. It is added at a ratio of $1.5 \mathrm{~mol}$ of mercaptoethanol to $1 \mathrm{~mol}$ of $\mathrm{SO}_{3}$. Dilution to a proinsulin $\left(\mathrm{S}_{-} \mathrm{SO}_{3}{ }^{-}\right)_{6}$ concentration of less than 1 $\mathrm{g} / \mathrm{L}$ is required to prevent cross-folding of proinsulin molecules. The reaction is carried out at 8 ${ }^{\circ} \mathrm{C}$ for 12 hours and reaches a yield of $85 \%$. After completion of the refolding step, the refolding reagents are replaced with WFI and the protein solution is concentrated using a diafiltration unit (DF-103) which has a product recovery yield of $95 \%$ (5\% of the protein denatures). The volume of the solution at this point is around 5,000 L. Next, the human proinsulin is chromatographically purified in a hydrophobic interaction chromatography column (C-102). The following operating assumptions were made: (1) the column is equilibrated for 30 minutes prior to loading, (2) the total resin binding capacity is $20 \mathrm{mg} / \mathrm{ml}$, (3) the eluant volume is equal to 6 column volumes (CV's), (4) the total volume of the solutions for column wash, regeneration and storage is 15 CV's, (5) the protein of interest is recovered in $1 \mathrm{CV}$ of eluant buffer with a recovery yield of 
$90 \%$, and (6) the material of a batch is handled in three cycles.

Enzymatic conversion. The removal of the C-peptide from human proinsulin is carried out enzymatically (using trypsin and carboxypeptidase B) in a reaction tank (V-108). Trypsin cleaves at the carboxy terminal of internal lysine and arginine residues, and carboxypeptidase $B$ removes terminal amino acids. The amount of trypsin used is rate-limiting and allows intact human insulin to be formed. Carboxipeptidase is added to a final concentration of $4 \mathrm{mg} / \mathrm{liter}$, while trypsin is added to a final concentration of $1 \mathrm{mg} /$ liter. The reaction takes place at $30^{\circ} \mathrm{C}$ for 4 hours and reaches a conversion yield of $95 \%$. The volume of the solution at this point is around 4,300 L.

\section{Final Purification Section}

A purification sequence based on multimodal chromatography, which exploits differences in molecular charge, size, and hydrophobicity, is used to isolate biosynthetic human insulin. A description of all the purification steps follows.

The enzymatic conversion solution is exchanged with WFI and concentrated by a factor of 4 in a diafilter (DF-103). An ion exchange column (C-103) is used to purify the insulin solution. The following operating assumptions were made: (1) the column is equilibrated for 30 minutes prior to loading, (2) the total resin binding capacity is $20 \mathrm{mg} / \mathrm{ml}$, (3) the eluant volume is equal to $8 \mathrm{CV}$ 's and the eluant is a $11.5 \% \mathrm{w} / \mathrm{w}$ solution of $\mathrm{NaCl}$ in WFI, (4) the total volume of the solutions for column wash, regeneration and storage is $14 \mathrm{CV}$ 's, (5) the protein of interest is recovered in $1.5 \mathrm{CV}$ of eluant buffer with a recovery yield of $95 \%$, and (6) the material from each batch is handled in four cycles. The liquid volume at this point is around $1,100 \mathrm{~L}$.

Next, the ion exchange eluant solution is exchanged with WFI in a diafilter (DF-105) and is concentrated by a factor of 2.0. A recovery yield of $98 \%$ was assumed for this step ( $2 \%$ denatures).

The purification of the insulin solution proceeds with a reverse phase high-pressureliquid-chromatography (RP-HPLC) step (C-104). Detailed information on the use of RP-HPLC for insulin purification is available in the literature. Analytical studies with a variety of reversedphase systems have shown that an acidic mobile phase can provide excellent resolution of insulin from structurally similar insulin-like components. Minor modifications in the insulin molecule resulting in monodesamido formation at the $21^{\text {st }}$ amino acid of the A chain, or derivatization of amines via carbamoylation or formylation, result in insulin derivatives which have significantly increased retention. Derivatives of this nature are typical of the kind of insulin-like components that are found in the charge stream going into the reversed-phase purification. The use of an acidic mobile phase results in elution of all the derivatives after the insulin peak, while the use of mildly alkaline $\mathrm{pH}$ results in derivatives eluted on either side of the parent insulin peak. An ideal $\mathrm{pH}$ for insulin purification is in the region of 3.0-4.0, since this $\mathrm{pH}$ range is far enough below the 
isoelectric $\mathrm{pH}$ of 5.4 to provide for good insulin solubility. An eluant buffer with an acetic acid concentration of $0.25 \mathrm{M}$ meets these operational criteria since it is compatible with the chromatography and provides good insulin solubility. A 90\% insulin yield was assumed in the RP-HPLC step with the following operating conditions: (1) the column is equilibrated for 30 minutes prior to loading, (2) the total resin binding capacity is $15 \mathrm{mg} / \mathrm{ml}$, (3) the column height is $25 \mathrm{~cm}$, (4) the eluant volume is equal to $6 \mathrm{CVs}$ and its composition is $25 \% \mathrm{w} / \mathrm{w}$ acetonitrile, $1.5 \%$ w/w acetic acid $73.5 \%$ w/w WFI, (5) the total volume of the solutions for column wash, equilibration, regeneration and storage is $6 \mathrm{CVs}$, and (5) the protein of interest is recovered in 1 CV of eluant buffer with a recovery yield of $90 \%$.

The RP-HPLC buffer is exchanged with WFI and concentrated by a factor of 2.0 in a diafilter (DF-105) that has a product recovery yield of $98 \%$ (2\% denatures). Purification is completed by a gel filtration chromatography column (C-105). The following operating assumptions were made: (1) the column is equilibrated for 30 minutes prior to loading, (2) the sample volume is equal to $5 \%$ of the column volume, (3) the eluant volume is equal to $4 \mathrm{CV}$ 's, (4) the total volume of the solutions for column wash, depyrogenation, stripping, and storage is 6 CV's, and (5) the protein of interest is recovered in $0.5 \mathrm{CV}$ of eluant buffer with a recovery yield of $90 \%$. The mobile phase is a solution of acetic acid.

Next, the same diafilter (DF-105) is used to concentrate the purified insulin solution by a factor of ten. The liquid volume at this point is around $500 \mathrm{~L}$, which contains approximately 12.8 $\mathrm{kg}$ of insulin. This material is pumped into a jacketed and agitated reaction tank (V-111).

Ammonium acetate and zinc chloride are added to the protein solution until each reaches a final concentration of $0.02 \mathrm{M}$ (Datar and Rosen, 1990). The $\mathrm{pH}$ is then adjusted to between 5.4 and 6.2. The crystallization is carried out at $5{ }^{\circ} \mathrm{C}$ for 12 hours. Insulin crystallizes with zinc with the following stoichiometry: insulin $6 \mathrm{Zn}_{2}$. Step recovery on insulin is around $90 \%$.

The crystals are recovered with a basket centrifuge (BCF-101)with a yield of $95 \%$. Finally, the crystals are freeze-dried (FDR-101). The purity of the crystallized end-product is between 99.5 and $99.9 \%$ measured by analytical high pressure liquid chromatography (HPLC). Approximately $11.31 \mathrm{~kg}$ of product is recovered per batch. The overall recovery yield is around $32 \%$.

\section{Material Balances and Environmental Impact Assessment}

Table 11-11 displays the raw material requirements in $\mathrm{kg}$ per year, per batch, and per $\mathrm{kg}$ of main product ( $\mathrm{MP}=$ purified insulin crystals). Note the huge amounts of WFI, water, formic acid, urea, guanidine hydrochloride, acetic acid, and acetonitrile required per $\mathrm{kg}$ of final product. All of these materials end up in waste streams. 
Table 11-11 Raw material requirements $(1$ batch $=11.31 \mathrm{e} \mathrm{kg} \mathrm{MP})$

\begin{tabular}{lrrr}
\hline Raw Material & $\mathbf{k g} /$ Year & $\mathbf{k g} /$ Batch & $\mathbf{k g} / \mathbf{k g ~ M P}$ \\
Glucose & 782,238 & 4,889 & 432.2 \\
Salts & 71,428 & 446 & 39.5 \\
Air & $3,647,536$ & 22,797 & $2,015.5$ \\
Ammonia & 75,689 & 473 & 41.8 \\
Water & $27,798,131$ & 173,738 & $15,360.6$ \\
NaOH $(0.5 \mathrm{M})$ & $5,548,731$ & 34,680 & $3,066.1$ \\
H3PO4 $(20 \%$ w/w) & $6,451,713$ & 40,323 & $3,565.1$ \\
TRIS Base & 43,200 & 270 & 23.9 \\
WFI & $61,446,154$ & 384,038 & $33,953.6$ \\
EDTA & 10,427 & 65 & 5.8 \\
Triton-X-100 & 3,035 & 19 & 1.7 \\
CNBr & 15,268 & 95 & 8.4 \\
Formic acid & $1,751,525$ & 10,947 & 967.9 \\
Urea & $3,062,697$ & 19,142 & $1,692.4$ \\
MrEtOH & 98,660 & 617 & 54.5 \\
NH4HCO3 & 5,551 & 35 & 3.1 \\
Sodium sulfite & 48,318 & 302 & 26.7 \\
Na2O6S4 & 24,159 & 151 & 13.4 \\
Guanidine HCl & 805,593 & 5,035 & 445.2 \\
Sodium Chloride & 778,032 & 4,863 & 429.9 \\
Sodium Hydroxide & 137,678 & 860 & 76.1 \\
Acetic-Acid & $2,435,170$ & 15,220 & $1,345.6$ \\
Enzymes & 3 & 0 & 0.0 \\
Acetonitrile & 767,190 & 4,795 & 423.9 \\
Ammonium Acetate & 181 & 1 & 0.1 \\
Zinc Chloride & 320 & 2 & 0.2 \\
Total & $\mathbf{1 1 5 , 8 0 8 , 6 3 1}$ & $\mathbf{7 2 3 , 8 0 4}$ & $\mathbf{6 3 , 9 9 3 . 0}$ \\
\hline
\end{tabular}

In the base case, it was assumed that this waste is treated and disposed of. However, opportunities may exist for recycling some chemicals for in-process use and recovering others for off-site use. For instance, formic acid $(\mathrm{HCOOH})$, acetonitrile, and urea are good candidates for recycling and recovery. Formic acid is used in large quantities (11 tons/batch) in the $\mathrm{CNBr}$ cleavage step (V-103) and it is removed using a rotary vacuum evaporator (CSP-101) along with small quantities of $\mathrm{CNBr}, \mathrm{H} 2 \mathrm{O}$, and urea. The recovered formic acid can be readily purified by distillation and recycled in the process. Around 2 tons/batch of urea are used for the dissolution of inclusion bodies (V-103) and 17 tons/batch is used in the first chromatography step (C-101) to purify proinsulin(S-SO3) 6 before its refolding. Approximately $90 \%$ of the urea appears in just two waste streams (Liq. Waste $4 \& 7$ ). It is unlikely that these urea-containing streams can be purified economically for in-process recycling. However, these solutions can be concentrated, neutralized, and shipped off-site for further processing and utilization as a nitrogen fertilizer.

Approximately 4.7 tons/batch of acetonitrile is used in the reversed-phase HPLC column (C-104) and most of it ends up in the waste stream of the column (Liq. Waste 13) along with 6.8 tons of water, 1.85 tons of acetic acid, and small amounts of $\mathrm{NaCI}$ and other impurities. It is unlikely that acetonitrile can be recovered economically to meet the high purity specifications for 
a step so close to the end of the purification train. However, there may be a market for off-site use.

\section{Process Scheduling and Resource Tracking}

Figure 11-13 displays the scheduling and equipment utilization for three consecutive batches. The plant batch time is approximately 260 hours. This is the time required to go from the preparation of raw materials to final product for a single batch. However, since most of the equipment items are utilized for much shorter periods within a batch, a new batch is initiated every 48 hours. Multiple bars on the same line (e.g., for DS-101, DF-101, DF-103, and DF-105) represent reuse (sharing) of equipment by multiple procedures. White space represents idle time. The equipment with the least idle time between consecutive batches is the time (or scheduling) bottleneck (V-103 in this case) that determines the maximum number of batches per year. Its occupancy time (approximately 43.85 hours) is the minimum possible time between consecutive batches (also known as Minimum Effective Plant Batch Time). This plant operates around the clock and processes 160 batches per year.

The execution in time of the various procedures and their operations can be visualized in detail through the operations Gantt chart (see Figure 11-14). Note, for instance, the operations of procedure P-8 (IB solubilization). The TRANSFER_IN operation in that procedure runs in parallel with the CENTRIFUGE_1 operation of the previous procedure (P-14). This is the case because while the IB slurry is being centrifuged as part of P-14, the concentrate (solids stream of the centrifuge) is being pumped into the vessel (V-103) of P-8. If this detail is not captured in the model, the identification of the equipment time (scheduling) bottleneck may be incorrect.

Process scheduling is closely related to the determination of the annual capacity of a batch plant. In the sensitivity analysis section, we will see how changes in scheduling and installation of additional equipment can be used to increase plant throughput and reduce manufacturing cost. 


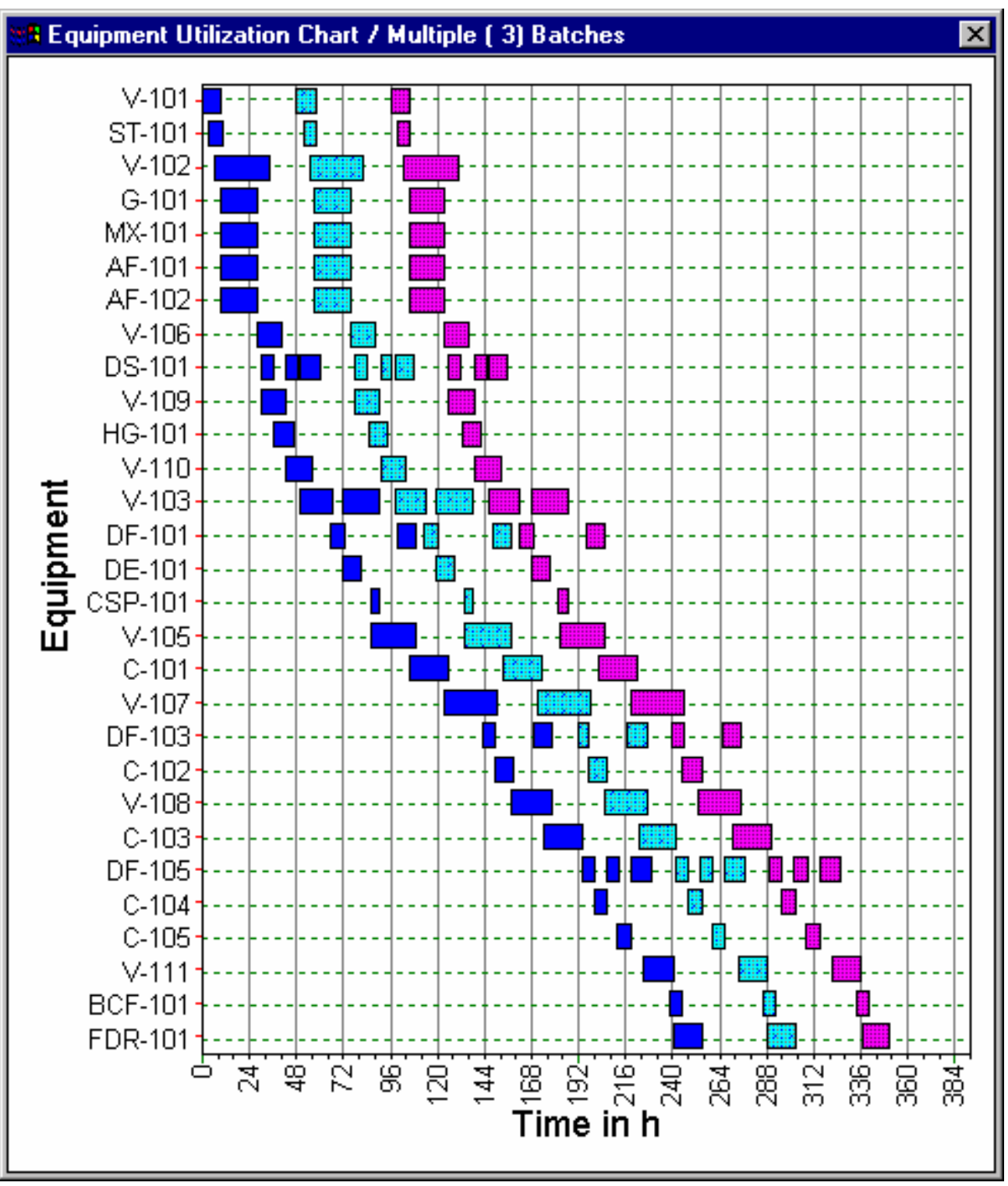

Figure 11-13 Equipment utilization as a function of time for three consecutive batches. 


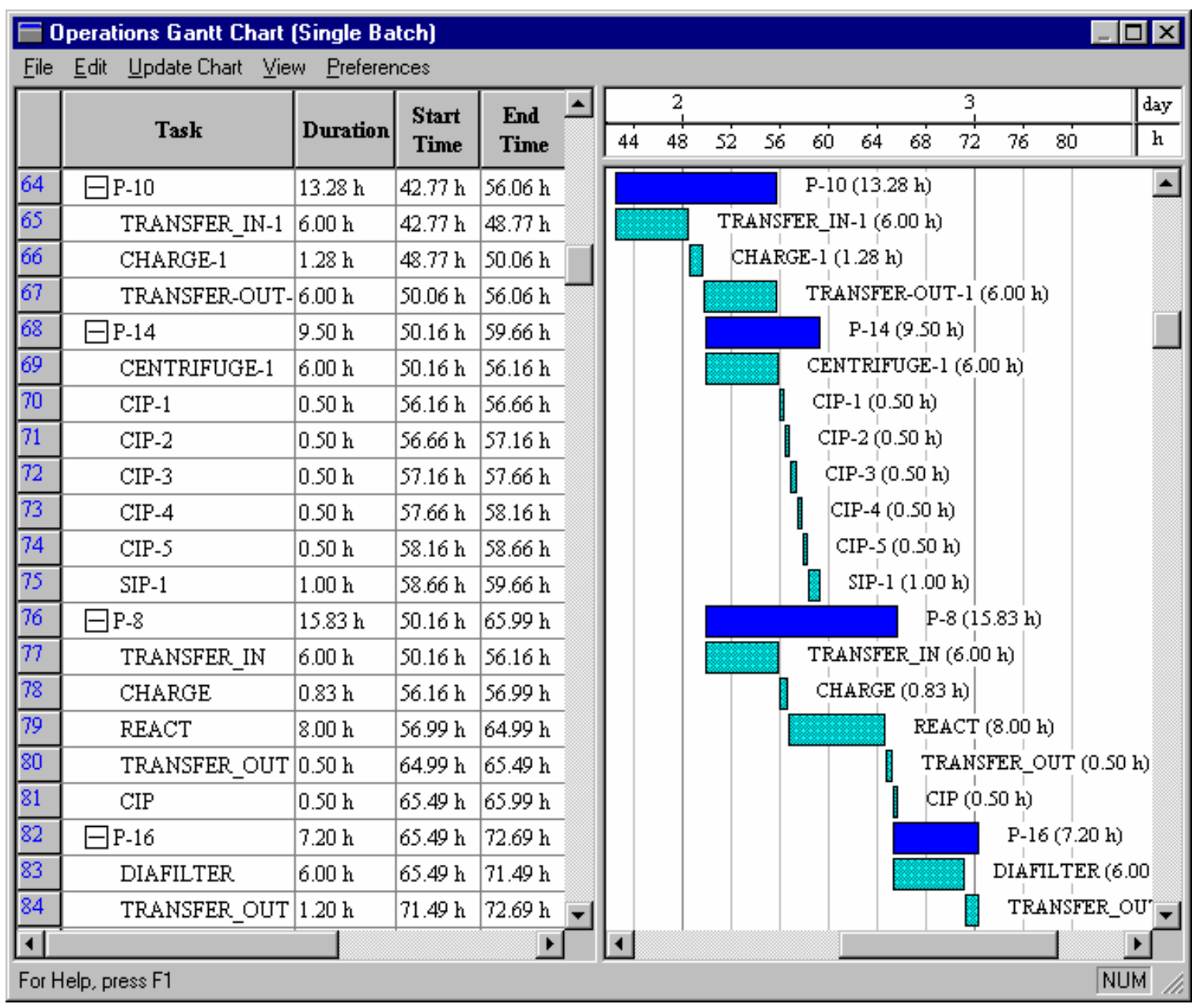

Figure 11-14 Operations Gantt chart.

Another characteristic of batch processing is the variable demand for resources (e.g., labor, utilities, and raw materials) as a function of time. For instance, Figure 11-15 displays the labor demand (expressed in number of operators) for 10 consecutive batches. Note that for short periods there is a need for up to 17 operators to be present. If that is not possible, then certain operations will need to be delayed in order to distribute the demand for operators more evenly. In such a case, the limited resource becomes the time bottleneck. Demand for steam and other utilities may also become a time bottleneck. The results of Figure 11-15 are also useful in staffing a facility. If the facility is dedicated to manufacturing of a single product, then, the number of operators in each shift should be based on the peak demand during that shift. In multi-product facilities, each production suite may employ a dedicated number of operators and utilize floating operators during periods of peak demand. 


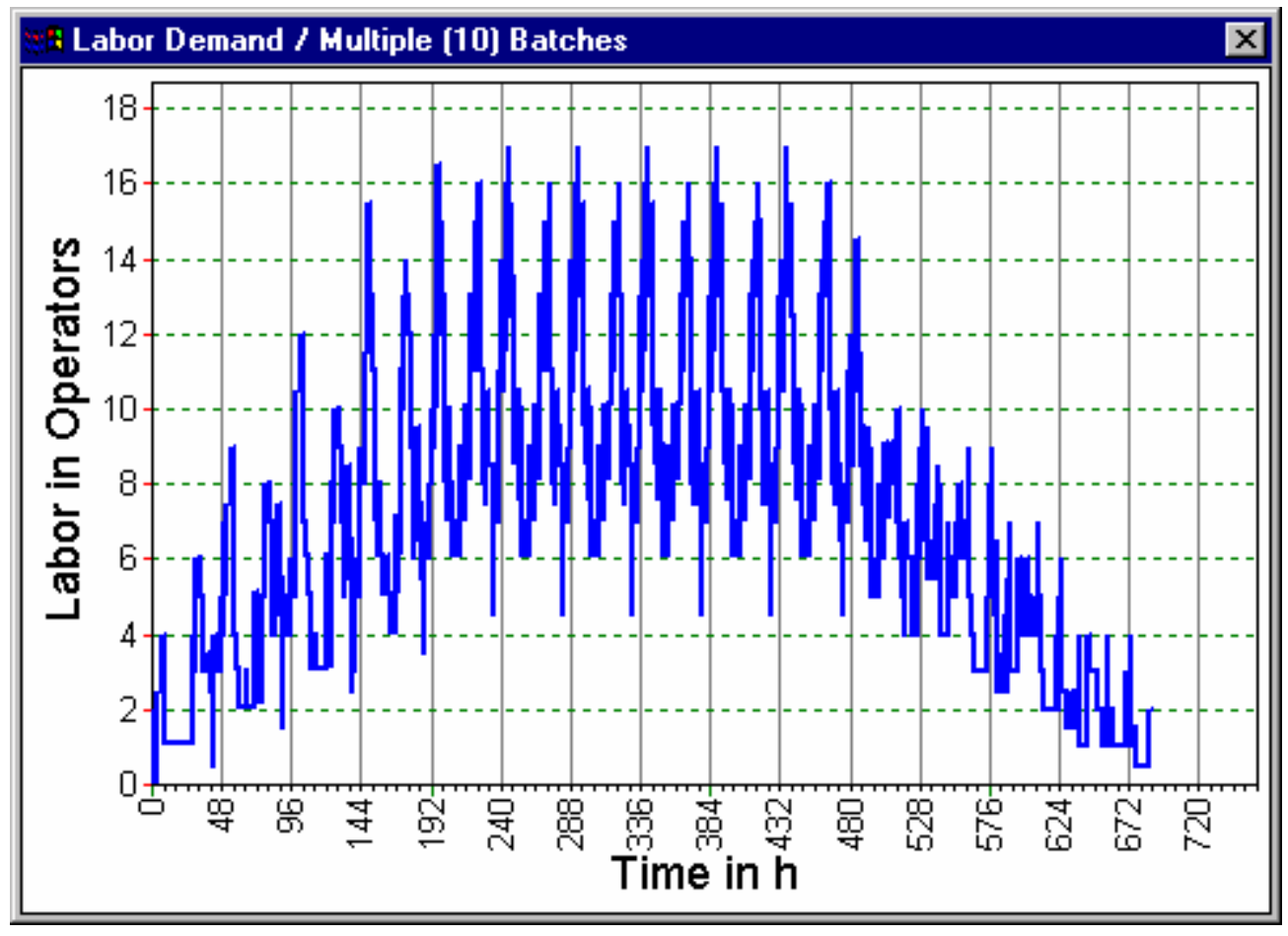

Figure 11-15 Labor demand as a function of time for ten consecutive batches.

\section{Economic Evaluation}

Table 11-12 shows the results of the economic evaluation. The detailed tables for these calculations are available as part of the demonstration version of SuperPro. For a plant of this capacity, the total capital investment is $\$ 78$ million. The unit production cost is $\$ 42.2 / \mathrm{g}$ of purified insulin crystals. Assuming a selling price of $\$ 75 / \mathrm{g}$, the project yields an after-tax internal rate of return (IRR) of 58.2\% and a net present value (NPV) of \$216 million (assuming a discount interest of 7\%). Based on these results, this project represents a very attractive investment. However, if amortization of up-front $R \& D$ costs is considered in the economic evaluation, the numbers change drastically. For instance, a modest amount of $\$ 100$ million for up-front R\&D cost amortized over a period of 10 years reduces the IRR to $17.7 \%$ and the NPV to \$121 million.

Figure 11-16 breaks down the operating cost. The cost of raw materials is the most important, accounting for $51 \%$ of the overall manufacturing cost. The equipment-dependent cost lies in the second position accounting for $16.9 \%$ of the overall cost. This cost item accounts for the depreciation and maintenance of the facility and other overhead expenses. Consumables account for $12.5 \%$ of the total cost. This represents the expense for periodically replacing the resins of the chromatography columns and the membranes of the membrane filters. Treatment and disposal of waste materials account for $11 \%$ of the total cost. As mentioned in the material balance section, recycling and reuse of some of the waste materials may reduce this cost. Labor lies in the fifth position accounting for $6.6 \%$ of the total cost. Approximately 50 operators are required to run the plant around the clock supported by 12 scientists for QC/QA work. The 
utilities cost is so low because it only accounts for electricity and the small amounts of heating and cooling required. The cost of purified water is treated as a raw material and not as a utility.

Table 11-12 Key economic evaluation results.

\begin{tabular}{ll}
\hline Direct Fixed Capital & $\$ 69.7$ million \\
Total Capital Investment & $\$ 78.0$ million \\
Plant Throughput & $1,810 \mathrm{~kg} /$ year \\
Manufacturing Cost & $\$ 76.5$ million/year \\
Unit Production Cost & $\$ 42.2 / \mathrm{g}$ \\
& \\
Selling Price & $\$ 75 / \mathrm{g}$ \\
Revenues & $\$ 135.7$ million/year \\
Gross Profit & $\$ 59.2$ million/year \\
Taxes (40\%) & $\$ 23.7$ million/year \\
Net Profit & $\$ 42.2$ million/year \\
& \\
IRR (after taxes) & $58.2 \%$ \\
NPV (for $7 \%$ discount interest) & $\$ 216$ million \\
\hline
\end{tabular}

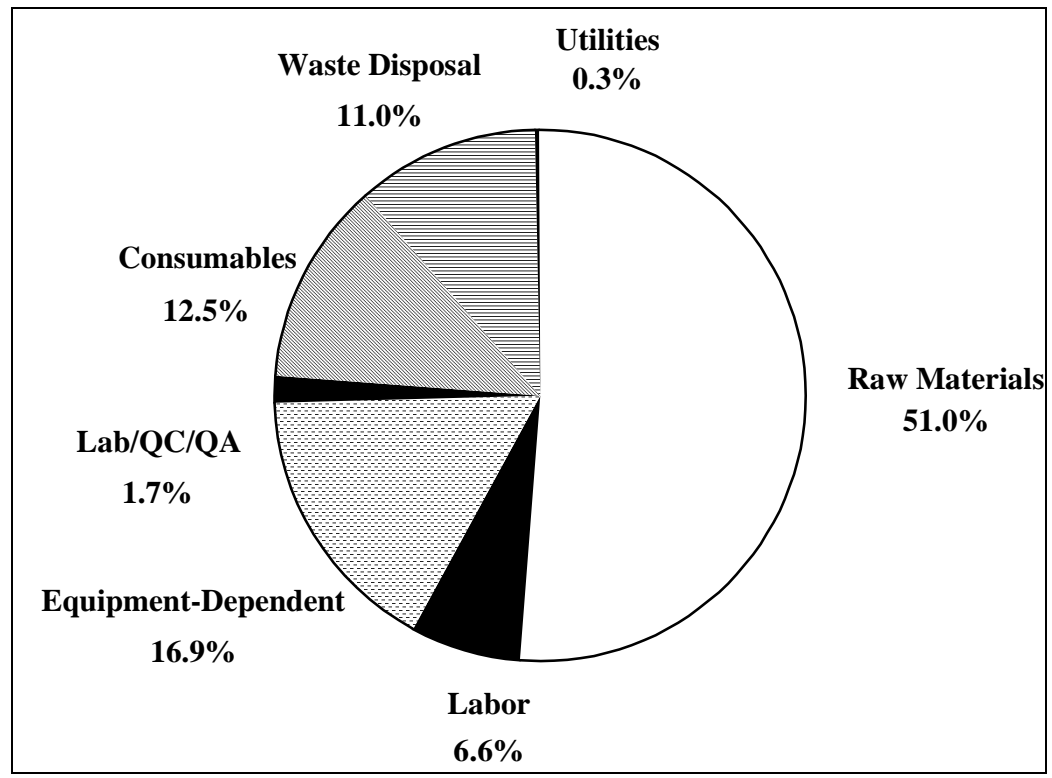

Figure 11-16 Breakdown of manufacturing cost.

Figure 11-17 displays the cost distribution per flowsheet section. Only $8.0 \%$ of the overall cost is associated with fermentation. The other $92 \%$ is associated with the recovery and purification sections. This is common for high value biopharmaceuticals that are produced from recombinant $E$. coli. Most of the cost is associated with the reactions section because of the large amounts of expensive raw materials and consumables that are utilized in that section. 


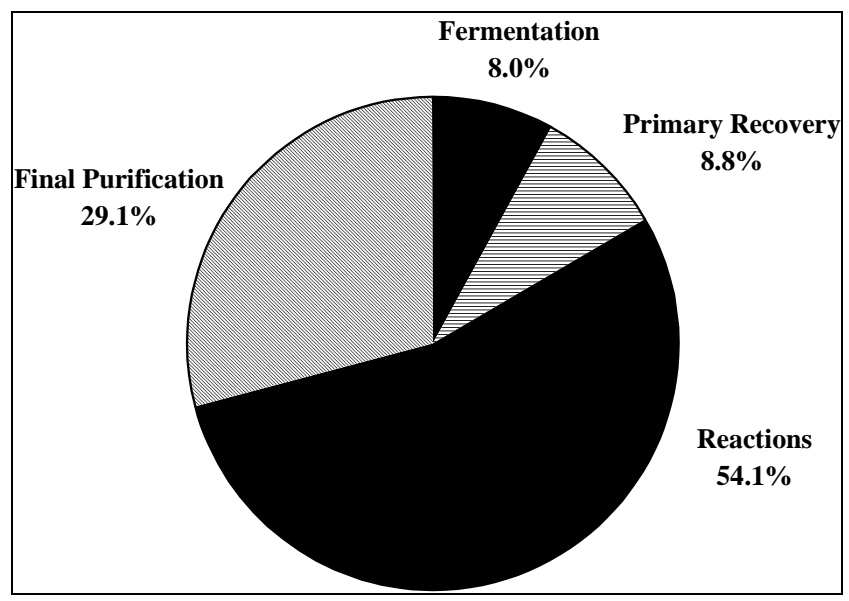

Figure 11-17 Cost distribution per flowsheet section.

Finally, Table 11-13 for each raw material displays its price, annual cost and contribution to the overall raw materials cost. $\mathrm{H}_{3} \mathrm{PO}_{4}(20 \% \mathrm{w} / \mathrm{w})$, WFI, acetic acid, urea, formic acid, acetonitrile, guanidine. $\mathrm{HCl}$, and the enzymes are the major contributors to the raw materials cost.

Table 11-13 Cost of raw materials.

\begin{tabular}{lrrr}
\hline Raw Material & Price (\$/kg) & Annual Cost (\$) & $\%$ \\
Glucose & 0.60 & 469,343 & 1.20 \\
Salts & 1.00 & 71,428 & 0.18 \\
Air & 0.00 & 0 & 0.00 \\
Ammonia & 0.70 & 52,983 & 0.14 \\
Water & 0.05 & $1,389,907$ & 3.56 \\
NaOH $(0.5 \mathrm{M})$ & 0.50 & $2,774,366$ & 7.11 \\
H3PO4 $(20 \% \mathrm{w} / \mathrm{w})$ & 1.00 & $6,451,713$ & 16.53 \\
TRIS Base & 6.00 & 259,200 & 0.66 \\
WFI & 0.10 & $6,144,615$ & 15.74 \\
EDTA & 18.50 & 192,902 & 0.49 \\
Triton-X-100 & 1.50 & 4,553 & 0.01 \\
CNBr & 11.00 & 167,953 & 0.43 \\
Formic acid & 1.60 & $2,802,441$ & 7.18 \\
Urea & 1.52 & $4,655,300$ & 11.93 \\
MrEtOH & 3.00 & 295,980 & 0.76 \\
NH4HCO3 & 1.00 & 5,551 & 0.01 \\
Sodium sulfite & 0.40 & 19,327 & 0.05 \\
Na2O6S4 & 0.60 & 14,495 & 0.04 \\
Guanidine HCl & 2.15 & $1,732,025$ & 4.44 \\
Sodium Chloride & 1.23 & 956,980 & 2.45 \\
Sodium Hydroxide & 3.50 & 481,875 & 1.23 \\
Acetic-Acid & 2.50 & $6,087,926$ & 15.60 \\
Enzymes & $3.091,128$ & 4.33 \\
Acetonitrile & 3.00 & $2,301,570$ & 5.90 \\
Ammonium Acetate & 15.00 & 2,718 & 0.01 \\
Zinc Chloride & 12.00 & 3,840 & 0.01 \\
Total & & $39,030,118$ & $\mathbf{1 0 0 . 0 0}$ \\
\hline & & &
\end{tabular}


The solution of $\mathrm{H}_{3} \mathrm{PO}_{4}$ is used for equipment cleaning. Other assumptions for the economic evaluation include: (1) a new manufacturing facility will be built and dedicated to production of $1,800 \mathrm{~kg} /$ year of purified insulin; (2) the entire direct fixed capital is depreciated linearly over a period of ten years; (3) the project life time is 15 years; (4) the unit cost of membranes is $\$ 200 / \mathrm{m}^{2}$ and they are replaced every 2,000 hours of operation; (5) the average unit cost of chromatography resins is $\$ 300 / \mathrm{L}$; (6) the waste disposal cost is $\$ 0.005 / \mathrm{L}$ for low BOD streams and $\$ 0.15 / \mathrm{L}$ for streams containing significant amounts of solvents and other regulated chemicals.

\section{Throughput Increase Options}

In the base case, a new batch is initiated every 48 hours. Most of the equipment items, however, are utilized for less than 24 hours per batch (see Figure 11-13). If the market demand for insulin grows, this provides the opportunity for increasing plant throughput without major capital expenditures. A realistic improvement is to initiate a batch every 24 hours. This will require a new fermentor of the same size whose operation will be staggered relative to the existing unit so that one fermentor is ready for harvesting every day. Such a production change will also require additional equipment of the following types: (1) disk-stack centrifuges to reduce the occupancy of DS-101 to less than 24 hours; (2) two reaction tanks to reduce the occupancy of V-103 and V-107; and (3) membrane filters to reduce the occupancy of DF-103 and DF-105.

The additional capital investment for such a change is around $\$ 20$ million. This additional investment will allow the plant's capacity to be doubled, and the new unit production cost will be around $\$ 33.6 / \mathrm{g}$. The reduction in the unit production cost is rather small because the majority of the cost is associated with raw materials, consumables, and waste disposal that scale approximately linearly with production.

\subsubsection{Therapeutic Monoclonal Antibody Production}

Monoclonal antibodies (MAb's) are used in diagnostic tests as well as for therapeutic purposes. World demand for currently approved MAb's is on the order of a few kilograms per year. However, new therapeutic MAb's are under development that require doses of several hundred milligrams to a gram over the course of therapy (Seaver, 1997). The world demand for such products will exceed $100 \mathrm{~kg}$ per year.

Current production choices for MAb's are limited to three well-established systems: ascites, stirred tank bioreactors (STR), and hollow-fiber bioreactors. Alternative technologies under development include transgenic animals and genetically altered plants (DeYoung, 1996). Currently, stirred tank bioreactors tend to be favored for production of MAb's in kilogram quantities. They are operated under batch, fed-batch, or perfusion mode. 
This example analyzes the production of a typical therapeutic monoclonal antibody. In the base case, approximately $6.2 \mathrm{~kg}$ of purified product is produced per year in 46 batches. The manufacturing cost for producing larger quantities is estimated as part of the sensitivity analysis.

\section{Process Description}

Upstream section. The entire flowsheet is shown in Figure 11-18. The serum-free and low-protein-content media powder is dissolved in WFI in a stainless steel tank (V-101), and the solution is sterilized using a $0.1 \mu \mathrm{m}$ dead-end polishing filter (DE-101). The concentration of media powder in the feed solution is $10 \mathrm{~g} /$ liter. A stirred-tank bioreactor ( $\mathrm{V}-102)$ is used to grow the cells that express the therapeutic immunoglobulin $\mathrm{G}(\mathrm{IgG})$. The bioreactor operates in fedbatch mode. A cycle time of 156 hours (132 hours for fermentation and 24 hours for turnaround) was assumed for the bioreactor. The volume of broth generated per bioreactor batch is approximately 2,200 liters containing $220 \mathrm{~g}$ of product (the product titer is $100 \mathrm{mg} / \mathrm{L}$ ). The total volume of the bioreactor vessel is 3,000 liters.

Downstream section. The generated biomass and other suspended compounds are removed using a $0.65 \mu \mathrm{m}$ membrane diafilter (DF-101). The product recovery yield of this step is $95 \%$. This filtration step takes $5.1 \mathrm{~h}$ and requires a membrane area of around $30 \mathrm{~m}^{2}$. The clarified solution is concentrated 20-fold using a 50,000 MW cut-off ultrafilter (UF-101). The recovery yield of this step is $95 \%$. This step takes $3.6 \mathrm{~h}$ and requires a membrane area of $40 \mathrm{~m}^{2}$. The bulk of the contaminant proteins are removed using a protein A affinity chromatography column (C101). The following operating assumptions were made: (1) resin binding capacity is $15 \mathrm{mg}$ of product per ml of resin; (2) the eluant is a $0.1 \mathrm{M}$ solution of sodium citrate, and its volume is equal to 6 column volumes (CV's); (3) the product is recovered in $3 \mathrm{CV}$ 's of eluant buffer with a recovery yield of $95 \%$, and the $\mathrm{pH}$ is maintained near neutral to ensure product stability; and (4) the total volume of the solutions for column equilibration, wash, and regeneration is $13 \mathrm{CV}$ 's. This step takes around $15.7 \mathrm{~h}$ and requires a resin volume of 24.5 liters. The protein A elution buffer is exchanged with phosphate buffer (procedure P-11) using the same diafilter (DF-101) as in P-7. The product recovery yield of this step is $95 \%$. The purification proceeds using a cationexchange chromatography column (C-102). The following operating assumptions were made: (1) the resin's binding capacity is $20 \mathrm{mg}$ of product per $\mathrm{ml}$ of resin; (2) a gradient elution step is employed with a sodium chloride concentration ranging from 0.0 to $1.0 \mathrm{M}$ and a volume of 6 CV's; (3) the product is recovered in 3 CV's of eluant buffer with a recovery yield of $90 \%$; and (4) the total volume of the solutions for column equilibration, wash, and regeneration is $17 \mathrm{CV}$ 's. This step takes around $13 \mathrm{~h}$ and requires a resin volume of 15.7 liters. Ammonium sulfate is added to a concentration of $2.0 \mathrm{M}$ to increase the ionic strength of the solution and prepare it for the hydrophobic interaction chromatography (HIC) step (C-103) that follows. The following operating assumptions were made for the HIC step: (1) resin-binding capacity is $20 \mathrm{mg}$ of product per $\mathrm{ml}$ of resin; (2) a gradient elution step is used in which the concentration of ammonium sulfate changes linearly from $2.0 \mathrm{M}$ to $0.0 \mathrm{M}$; (3) the product is recovered in $2 \mathrm{CV}$ 's of eluant buffer with a recovery yield of $95 \%$; and (4) the total volume of the solutions for column 
equilibration, wash, and regeneration is 22 CV's. This step takes around 13.5 hours and requires a resin volume of 15.7 liters. The purified product solution is concentrated two-fold and the HIC elution buffer is exchanged with phosphate buffer using the same diafilter (P-17 \DF-101).

Next, glycerol is added (for product stability) to a concentration of $100 \mathrm{~g} / \mathrm{L}$ and the solution is sent to product formulation. The product concentration in the final solution is around 8 $\mathrm{g} /$ liter. The following additional assumptions were made: (1) WFI is used for the preparation of water solutions and buffers; (2) to calculate the cycle time of chromatography steps, it was assumed that loading and elution operate at a linear velocity of $100 \mathrm{~cm} / \mathrm{h}$, while equilibration, washing, and regeneration operate at a linear velocity of $200 \mathrm{~cm} / \mathrm{h}$.

\section{Material balances}

Table 11-14 provides a summary of the overall material balances per batch. The quantities are in kilograms per batch. The duration of a single batch is $162 \mathrm{~h}$. The overall recovery yield of $\mathrm{IgG}$ (the product) is $62 \%$ (140 $\mathrm{g}$ of $\mathrm{IgG}$ is recovered out of the $220 \mathrm{~g}$ that is present in the fermentation broth). Note the large amount of process water and WFI utilized per batch. The majority of process water and WFI are utilized for equipment cleaning.

Table 11-14 Overall material balances (kg/batch)

\begin{tabular}{|lrrr|}
\hline COMPONENT & Total Inlet & Total Outlet & Product \\
\hline Ammonium Sulfate & 64.69 & 64.69 & \\
Biomass & 0.00 & 0.87 & \\
Glycerol & 1.85 & 1.85 & \\
IgG & 0.00 & 0.22 & 0.14 \\
Growth Media & 21.76 & 8.41 & \\
Na3Citrate & 0.80 & 0.80 & \\
Phosphoric Acid & $1,041.00$ & $1,041.00$ & \\
Sodium Hydrophosphate & 6.83 & 6.81 & \\
Sodium Chloride & 55.18 & 55.19 & \\
Sodium Hydroxide & 6.83 & 6.81 & \\
Tris-HCl & 0.69 & 0.69 & \\
Water & $11,459.00$ & $11,458.00$ & \\
WFI & $18,269.00$ & $18,269.00$ & \\
\hline TOTAL & $\mathbf{3 0 , 9 2 8 . 0 0}$ & $\mathbf{3 0 , 9 2 8 . 0 0}$ & $\mathbf{0 . 1 4}$ \\
\hline
\end{tabular}

\section{Process scheduling}

Figure 11-19 displays the scheduling and equipment utilization for two consecutive batches. The plant batch time is approximately $232 \mathrm{~h}$. This is the time required to go from the preparation of raw materials to the final product in a single batch. A new batch is initiated every seven days (168 h). The bioreactor, which is the time (scheduling) bottleneck, has a cycle time of $152 \mathrm{~h}$ ( $140 \mathrm{~h}$ for fermentation and $12 \mathrm{~h}$ for turnaround). While the bioreactor is preparing a new batch, the downstream equipment is being 


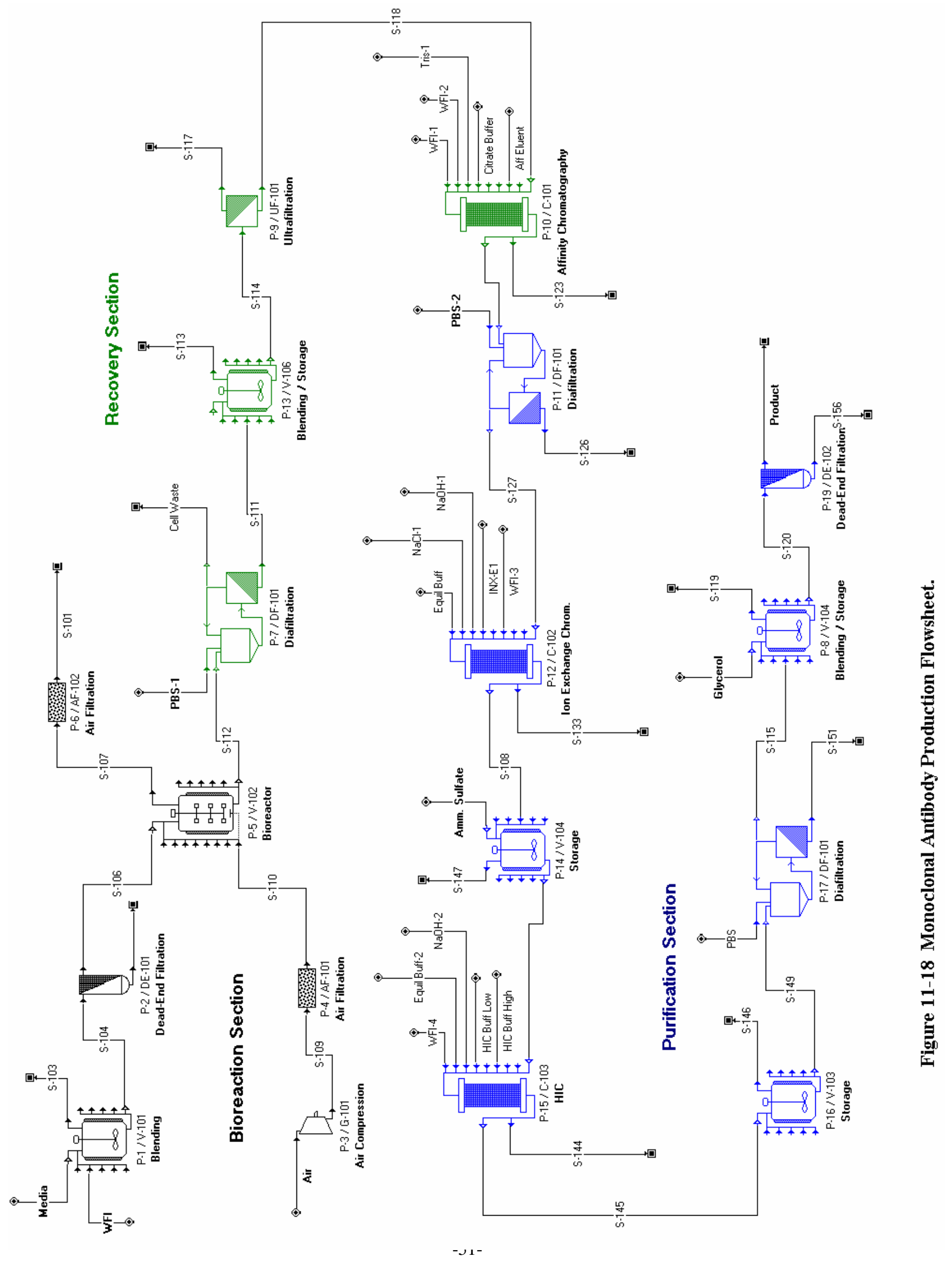


utilized to purify the product of the previous batch. The downstream section requires two shifts per day for four days a week. Multiple bars on the same line (e.g., for DF-101 and $\mathrm{V}-104$ ) represent reuse (sharing) of equipment by multiple procedures. White space represents idle time. On an annual basis, the plant processes 46 batches and produces 6.2 $\mathrm{kg}$ of purified IgG.

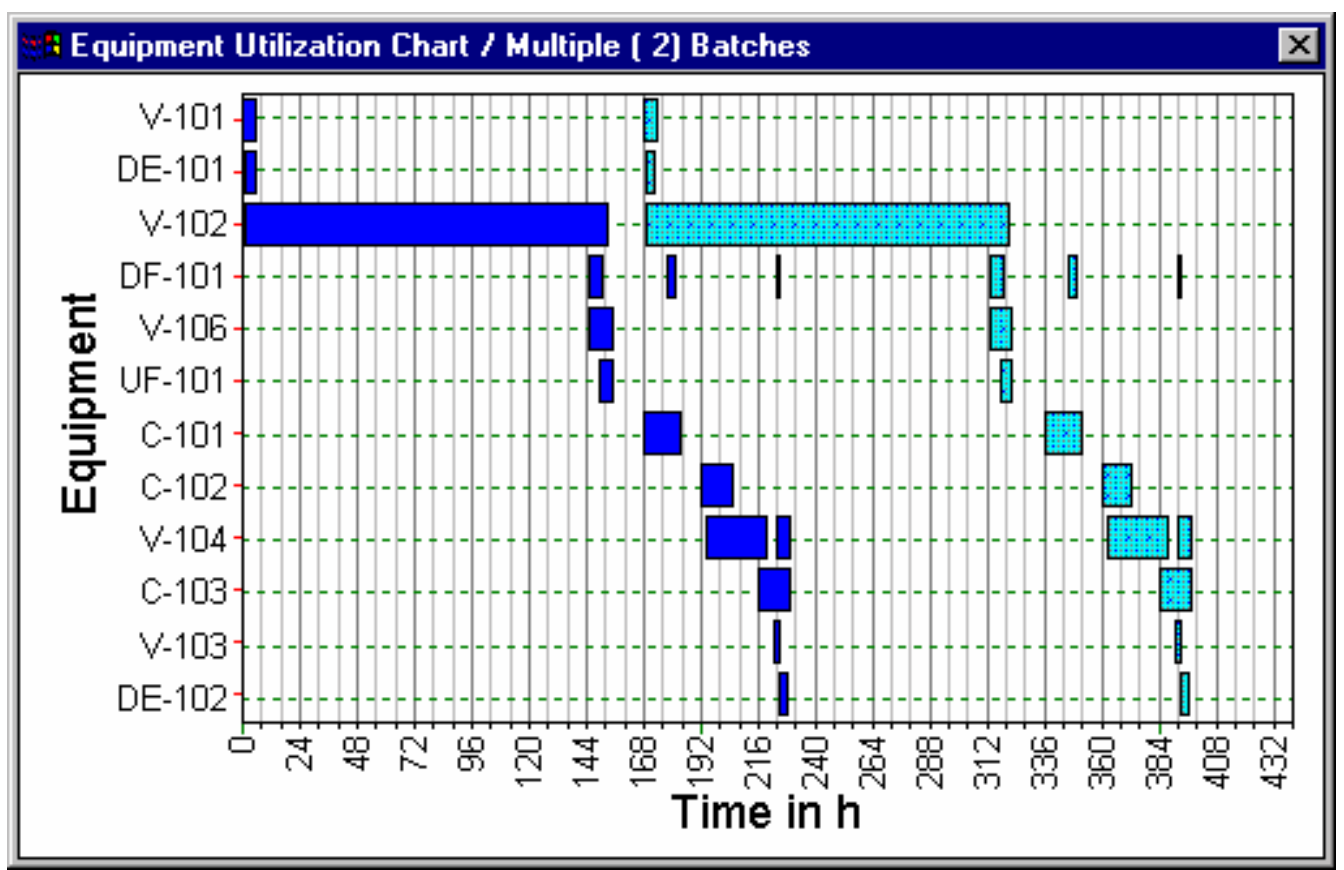

Figure 11-19 IgG production scheduling Gantt chart (two consecutive batches).

\section{Economic evaluation}

Table 11-15 shows the key economic evaluation results generated using the built-in cost functions of SuperPro Designer. For the base case ( $6.2 \mathrm{~kg} /$ year of $\operatorname{IgG})$, the total capital investment is around $\$ 16.3$ million. The floor area of the production facility is around 2,000 $\mathrm{m}^{2}$. The unit production cost is around $\$ 900 / \mathrm{g}$ of purified IgG. Assuming a selling price of $\$ 2,500 / \mathrm{g}$, the project yields an after-tax internal rate of return (IRR) of $47.4 \%$ and a net present value (NPV) of $\$ 32.5$ million (assuming a discount interest of 7\%). However, as with the insulin example, if amortization of up-front $R \& D$ cost is considered in the economic evaluation, the numbers change drastically. For instance, a modest amount of $\$ 20$ million for up-front $R \& D$ cost amortized over a period of 10 years reduces the IRR to $20 \%$ and the NPV to $\$ 12.5$ million.

Figure 11-20 breaks down the operating cost. The equipment-dependent cost is the most important item, accounting for $50 \%$ of the manufacturing cost. This is common for high value products that are produced in small quantities. Labor lies in the second position accounting for $16 \%$ of the total cost. Eight operators are required to run the plant supported by four scientists for QC/QA work. Raw materials and consumables account for $11 \%$ and $13 \%$, respectively. 
Table 11-15 Key economic evaluation results.

\begin{tabular}{|l|l|}
\hline Direct Fixed Capital & $\$ 15.3$ million \\
Total Capital Investment & $\$ 16.3$ million \\
Plant Throughput & $6.2 \mathrm{~kg}$ of IgG/year \\
Manufacturing Cost & $\$ 5.64$ million/year \\
Unit Production Cost & $\$ 908 / \mathrm{g}$ of IgG \\
& \\
Selling Price & $\$ 2,500 / \mathrm{g}$ of IgG \\
Revenues & $\$ 15.5$ million/year \\
Gross Profit & $\$ 9.9$ million/year \\
Taxes (40\%) & $\$ 4.0$ million/year \\
Net Profit & $\$ 7.4$ million/year \\
IRR (after taxes) & $47.4 \%$ \\
NPV (for $7 \%$ discount interest) & $\$ 32.5$ million \\
\hline
\end{tabular}

Consumables include the cost of chromatography resins and membrane filters that need to be replaced on a regular basis. In terms of cost distribution per section, $46 \%$ of the cost is associated with the upstream section and 54\% with the downstream.

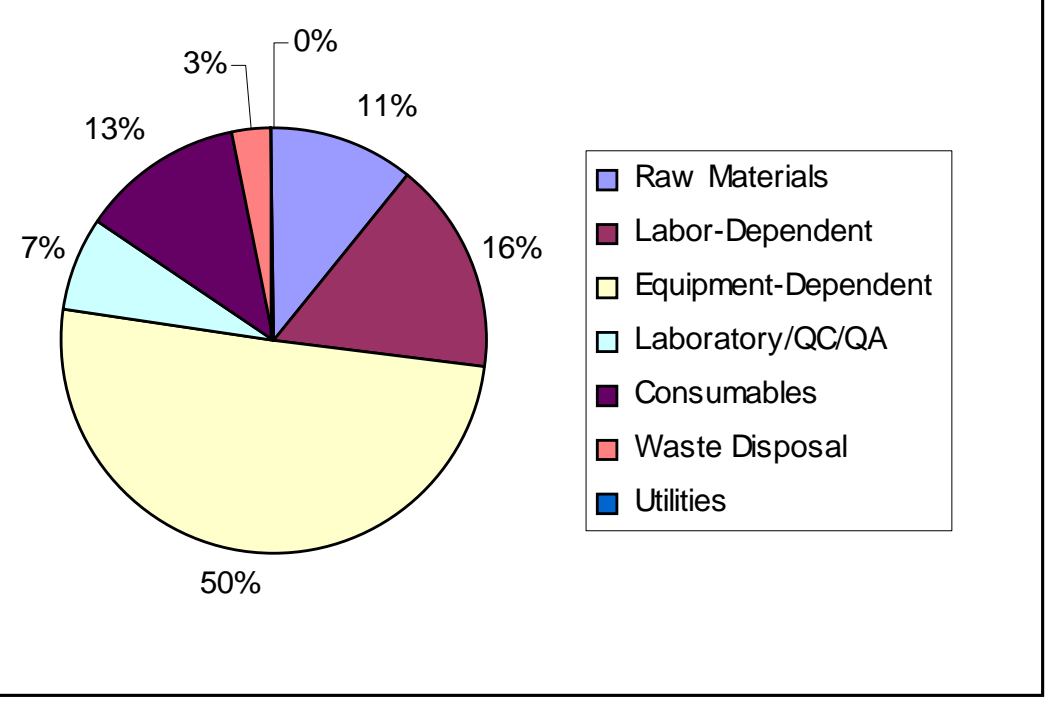

Figure 11-20 Breakdown of manufacturing cost.

Key assumptions for the economic evaluation include: (1) a new manufacturing facility will be built and dedicated to production of $6.2 \mathrm{~kg} /$ year of $\mathrm{IgG}$; (2) the entire direct fixed capital is depreciated linearly over a period of ten years; (3) the project lifetime is 15 years; (4) the unit cost 
of WFI is $\$ 0.1 / \mathrm{L}$; (5) the cost of media is $\$ 5 / \mathrm{L}$ (based on volume of solution fed to bioreactors);

(6) all of the chemicals used are of high purity grade; (7) the unit cost of membranes is $\$ 350 / \mathrm{m}^{2}$;

(8) the unit cost of chromatography resins is $\$ 6,000 / \mathrm{L}, \$ 1,600 / \mathrm{L}, \$ 3,200 / \mathrm{L}$ for columns $\mathrm{C}-101$, C102, and C-103, respectively; (9) the chromatography resins are replaced every 20 cycles; and (10) the average waste disposal cost is $\$ 0.5 / \mathrm{kg}$.

\section{Sensitivity analysis}

After a model for the entire process is developed on the computer, tools like SuperPro Designer can be used to ask and readily answer "what if" questions and carry out sensitivity analysis with respect to key design variables. In this example, we looked at the impact of product

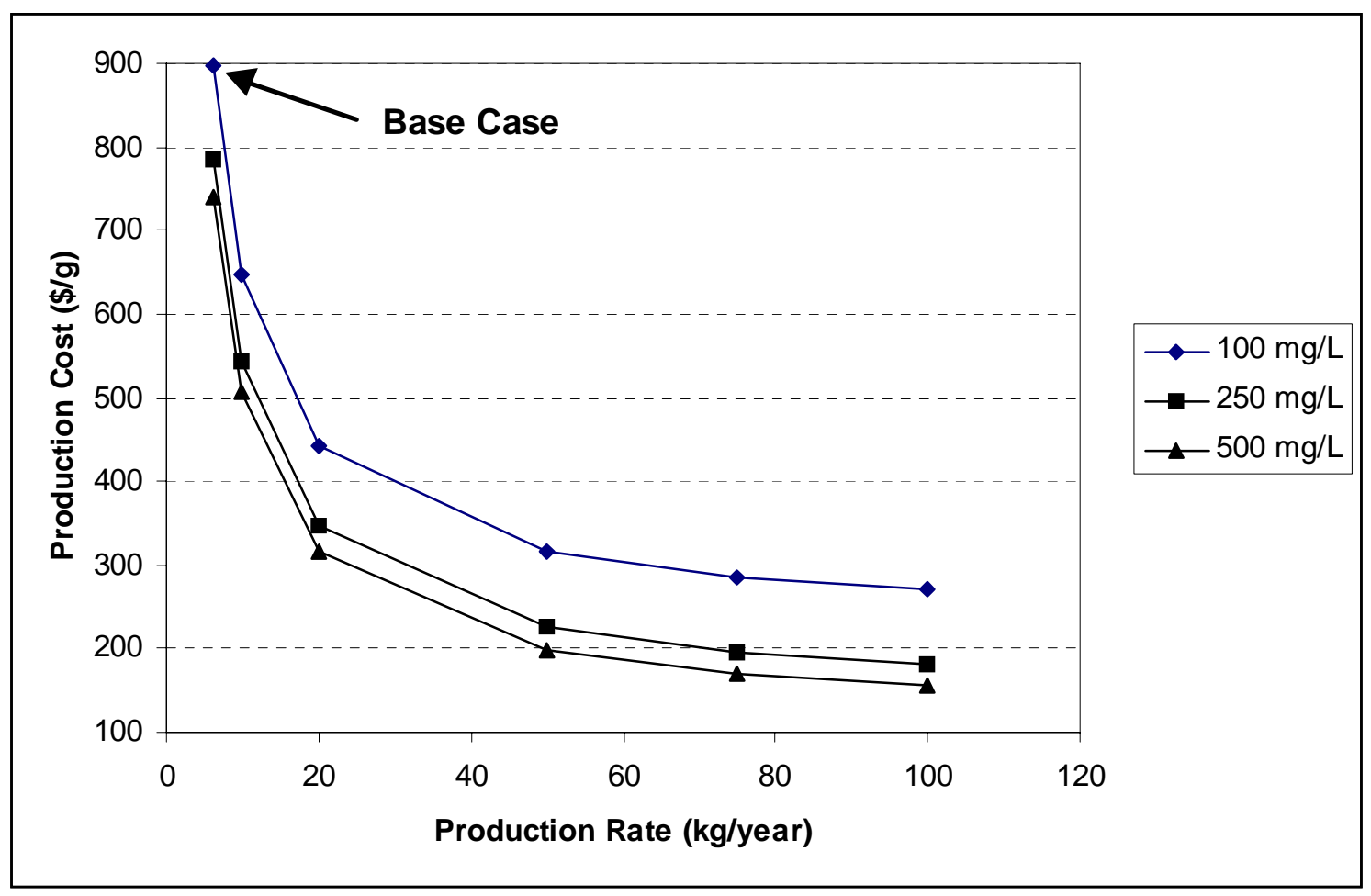

Figure 11-21 Production cost as a function of product titer and production rate.

titer (in the bioreactor) and production rate on unit production cost. For a product titer of 100 $\mathrm{mg} / \mathrm{L}$, the cost drops considerably for production rates of up to $80 \mathrm{~kg} /$ year of purified $\mathrm{IgG}$ (see Figure 11-21). For higher production rates, the cost levels off and approaches a value of $\$ 260 / \mathrm{g}$. Increasing the titer from $100 \mathrm{mg} / \mathrm{L}$ to $250 \mathrm{mg} / \mathrm{L}$ reduces the production cost by $\$ 90-110 / \mathrm{g}$, depending on production rate. The reduction in cost is smaller (in the range of $\$ 30 / \mathrm{g}$ to $\$ 45 / \mathrm{g}$ ) when the product titer is increased from $250 \mathrm{mg} / \mathrm{L}$ to $500 \mathrm{mg} / \mathrm{L}$. As can be seen from Figure 1121 , the production cost reaches a minimum of $\$ 150 / \mathrm{g}$ as we increase throughput and product titer. For throughputs in the range of $100 \mathrm{~kg} /$ year and titers of $500 \mathrm{mg} / \mathrm{L}$, almost $80 \%$ of the manufacturing cost is associated with the downstream section. Furthermore, under such 
conditions the cost of purification scales approximately linearly with production rate, because most of the cost is associated with purification raw materials and consumables. Therefore, less expensive product formation options, such as transgenic animals and genetically altered plants, can only have an impact on the $20 \%$ of the total cost associated with product formation. In other words, the cost of MAb's will not drop below $\$ 120 / \mathrm{g}$ (80\% of $\$ 150 / \mathrm{g})$, no matter what upstream technology is used. The only way to go below the $\$ 120 / \mathrm{g}$ barrier is by developing less expensive product purification technologies and deploying them in combination with inexpensive upstream technologies (such as transgenic animals).

Key assumptions for the sensitivity analysis are that (1) the composition of fermentation media is independent of product titer; and (2) the scheduling is independent of plant throughput (as we increase throughput, we continue to process 44 batches per year by utilizing larger and multiple pieces of the same type of equipment).

\section{PROBLEMS}

\subsection{Tissue Plasminogen Activator}

Tissue plasminogen activator (tPA) was among the first products of biotechnology to be based on recombinant DNA technology. tPA is a medium molecular weight enzymatic protein whose primary application is in the treatment of myocardial infarction (heart attack) patients. First characterized in 1979, the protein was commercially developed by Genentech, with clinical

trial quantities and purities being achieved in late 1984. The current market demand is around 15 $\mathrm{kg} / \mathrm{yr}$ of purified tPA, which generates annual revenues of around $\$ 300$ million for Genentech. The typical dose of tPA is around $100 \mathrm{mg}$ and this corresponds to a price per dose of around $\$ 2,000$.

The management of your company believes that the world demand can increase to more than $200 \mathrm{~kg}$ per year if the price per dose is reduced to around $\$ 300$. Before committing to the venture, your president would like you, as Director of Corporate Planning, to evaluate a technology for producing $50 \mathrm{~kg}$ of tPA per year using transgenic goats. Based on data from Genzyme Transgenics, you know that you can buy milk containing tPA at a concentration of 20 $\mathrm{g} / \mathrm{L}$ for around $\$ 200 / \mathrm{g}$ of tPA.

Based on information from the technical and patent literature, develop and evaluate a process that can recover and purify $50 \mathrm{~kg}$ of tPA per year from goat milk. More specifically, estimate the capital investment required and the unit production cost. 


\subsection{Indigo}

Indigo is a dye that is used by denim manufacturers (to make blue jeans). It has been traditionally produced through chemical synthesis. The chemical route, however, generates large amounts of regulated waste materials that make the process environmentally unattractive. In the late 1990's, Genencor International (a biotechnology company) commercialized a technology for producing indigo via fermentation.

Based on information from the technical and patent literature, develop and evaluate a process for producing 5,000,000 kg of indigo per year via fermentation. The product must meet the quality specifications of the denim industry. More specifically, estimate the capital investment required and the unit production cost.

\subsection{L-lysine}

L-lysine is an amino acid that is produced in large quantities (over 100,000 metric tons per year) via fermentation. It is used as an animal feed supplement mainly for poultry and pigs.

Based on information from the technical and patent literature, develop and evaluate a process for producing 15,000,000 kg of L-lysine per year via fermentation. Your analysis should include estimation of capital and operating cost.

\subsection{Xanthan Gum}

Xanthan gum is a water-soluble polysaccharide produced via fermentation. It is used in food products as a thickener, stabilizer and an emulsifier. Xanthan gum is also used for enhanced oil recovery.

Based on information from the technical and patent literature, develop and evaluate a process for producing $10,000,000 \mathrm{~kg}$ of xanthan gum per year. The product should meet the specifications of the petroleum industry for enhanced oil recovery. Your analysis should include estimation of capital and operating cost. Also, perform sensitivity analysis and estimate the unit production cost for plant capacities ranging from 10 to 50 million $\mathrm{kg}$ of xanthan gum per year.

\subsection{Biodegradable Polymers}

Because of the capacity limitations of urban landfills, biodegradable plastic packaging materials are of interest as a means to reduce the load of solid waste disposal systems.

Poly-2-hydroxybutyrate (PHB), a biodegradable polyester, is such a promising material that can be produced via fermentation. Microorganisms that synthesize PHB include Gram positive and Gram negative species and cyanobacteria. Some members of the groups of Alcaligenes and Azotobacter are the most promising because they store high levels of PHB. PHB 
is synthesized and stored intracellularly as a possible future carbon and energy source. High levels of polymer are obtained under nitrogen and phosphorous limitation. At optimum conditions, PHB can reach $70-80 \%$ by weight of the cell mass of the organism.

Based on information from the technical and patent literature, design and evaluate a plant that produces $30,000,000 \mathrm{~kg}$ of PHB per year. Your analysis should include estimation of capital and operating costs.

\subsection{Detergent Enzymes}

Proteolytic enzymes are used in detergents to hydrolyze and remove proteinaceous stains. The commercially important proteolytic enzymes that are used in detergents are mainly produced by Bacillus subtilis and Bacillus licheniformis. These enzymes are endo-cleaving, have broad specificity, are active over a wide $\mathrm{pH}$ range and calcium improves their stability at high temperature or extremes of $\mathrm{pH}$. Their molecular weight is around 30,000 and their isoelectric point is in the range of 8.5-9.5.

The current world demand for detergent enzymes is around 10,000 metric tons (of pure enzyme) per year, corresponding to a world market of around $\$ 300$ million.

The marketing department of your company believes that the world demand can increase to more than 20,000 metric tons per year if the selling price is reduced to around $\$ 15 / \mathrm{kg}$ of pure enzyme. Before committing to the venture, your company would like you to evaluate the cost structure of the current producers and find out if it is possible (through the use of genetic engineering and modern separation technologies) to produce such enzymes for less than $\$ 10 / \mathrm{kg}$.

\subsection{Therapeutic Proteins from Transgenic Tobacco}

Transgenic plants (e.g., corn, tobacco, etc.) have the potential to produce complex bioactive proteins at significantly lower cost than production via transgenic animals or mammalian cell cultures. The advantages of transgenic plant production are easy and efficient introduction of stable foreign genes, cost-effective biomass production ( $\$ 0.02$ to $\$ 0.04$ per $\mathrm{kg}$ ), no possible contamination with human disease agents, and the ability to perform complex protein processing needed for many bioactive human therapeutics. Cost-effective biomass production makes this mode of production suitable for large volume recombinant proteins. The ability to perform complex protein processing is advantageous for production of therapeutic glycoproteins and bioactive peptides. Downstream processing costs are a major portion of the total unit production cost associated with transgenic plant production of large volume therapeutic proteins. Therefore, primary recovery requires significant volume reduction. Once volume reduction and biomass 
removal are achieved, chromatographic purification is required to remove plant protein impurities.

Design a purification process for use in a facility manufacturing 100 metric tons per year of a recombinant human blood protein from transgenic tobacco. Assume that the expression level is $0.5 \mathrm{~g}$ of product protein per $\mathrm{kg}$ of tobacco. Assume that biomass production and primary recovery are performed at a separate site. The feed to the purification section is $4,000 \mathrm{~L}$ per day (containing $200 \mathrm{~g} / \mathrm{L}$ of product protein) and this material is purchased for $\$ 0.5 / \mathrm{g}$ of product protein. The process should include the appropriate filtration and chromatographic steps. Assume that a combination of affinity and ion exchange chromatography provide $>90 \%$ pure product. (Source: Steve Griffiths, MIT, Chemical Engineering Department)

\section{REFERENCES}

Asenjo, J. and F. Maugeri (1991). An expert system for selection and synthesis of protein purification processes, in Frontiers in Bioprocessing II, (Todd, P., S.K. Sikdar and M. Bier, ad.), ACS Books, Washington.

Atkinson B. and F. Mavituna (1991). Biochemical Engineering and Biotechnology Handbook, 2nd edition, Stockton Press (MacMillan Publishers), 447-519.

Axelsson, H.A.C. (1985). Centrifugation, in Comprehensive Biotechnology, (Murray MooYoung, ed.), Vol. 2., Pergamon Press.

Barfoed, H.C. (1987). Insulin Production Technology, Chem. Eng. Prog, 83, 49-54.

Bjurstrom Ed (1985). Biotechnology, Chemical Engineering, February issue.

Blanch H.W. and D.S. Clark (1997). Biochemical Engineering, Marcel Dekker, New York.

Brunner, K.H. and H. Hemfort (1988). Centrifugal Separation in Biotechnological Processes, in Advances in Biotechnological Processes, Vol. 8, (Mizrahi, A. ed.), Alan R. Liss,Inc., NY.

Chang, Y.-K. and H.A. Chase (1996). Development of operating conditions for protein purification using expanded bed techniques: The effect of the degree of bed expansion on adsorption performance, Biotech. \& Bioeng., 49, 512-526.

Chan. M.Y.Y., M. Hoare, and P. Dunnill (1986). The Kinetics of Protein Precipitation by Different Reagents, Biotechnology and Bioengineering, Vol. XXVIII, 387-393.

Crueger W. and A. Crueger (1989). BIOTECHNOLOGY - A Textbook of Industrial Microbiology, 2nd edition, Sinauer Associates, Inc., Sunderland, MA.

Data, R. and C.-G. Rosen (1990). Downstream process economics, 741-793. In Separation Processes in Biotechnology, (Asenjo, J.A, ed.), Marcel Dekker, NY. 
DeYoung, H.G. (1996). Multiple Choices for Monoclonal Production. Genetic Engineering News, 16 No. 14. 12-33.

Dlouhy, P.E. and d.A. Dahlstrom (1968). Continuous Filtration in Pharmaceutical Processing, Chemical Engineering Progress, 64, No. 4, 116-121.

Douglas, J.M. (1988). Conceptual Design of Chemical Processes, McGraw-Hill, New York.

Fish, W.W., A. Danielson, K. Nordling, S.H. Miller, C.F. Lam, and I. Bjork (1985). Denaturation Behavior of Antithrombin in Guanidinium Chloride, Biochemistry, 24, 1510-1517.

Freese H.L. (1993). Evaporation, in Fermentation and Biochemical Engineering Handbook, (Vogel, H.C., ed.), Noyes Publications, Park Ridge, New Jersey, 227-242.

Frohlich, B.T. (1999). Considerations for Developing In-house Capabilities for Cost of Goods Estimation, in Biopharmaceutical Process Economics and Optimization (conference proceedings), September 30 - October 1, 1999, International Business Communications (publisher).

Garrett, D.E. (1989). Chemical Engineering Economics, Van Nostrand Reinhold, New York.

Kalk, J.P., and A.F. Langlykke, (1986). Cost estimation for biotechnology projects, in Manual of Industrial Microbiologyand Biotechnology (Demain A.L. and Solomon N.A. ed.),. American Society for Microbiology, Washington, D.C., 363-385.

Kehoe, J.A. (1989). The Story of Biosynthetic Human Insulin, 45-49. In Frontiers in Bioprocessing, (Sikdar, S.K, M. Bier, and P. Todd, editors.), CRC Press, Inc., Boca Raton, FL.

Kula, M.-R. and Horst S. (1987). Purification of Proteins and the Disruption of Microbial Cells, Biotechnology Progress, 3, No.1.

Leser, E.W. and J.A. Asenjo (1992). Rational design of purification processes for recombinant proteins, Journal of Chromatography, 584, 43-57.

Ladisch, M.R. and Kohlmann, K.L. (1992). Recombinant Human Insulin, Biotechnology.

Progress, 8, 469-478.

Palmer, D.E. (1977). High Purity Protein Recovery, Process Biochemistry, June, 24-28.

Peters, Max S., and Klaus D. Timmerhaus (1991). Plant Design and Economics for Chemical Engineers, 4th edition, McGraw-Hill, NY.

Petrides, D.P., C.L. Cooney, and L.B. Evans (1989). An Introduction to Biochemical Process Design, in Chemical Engineering Problems in Biotechnology, (Shuler, M.L, ed.), Vol. 1, AIChE, 351-372.

Petrides, D.P. (1994). BioPro Designer - An Advanced Computing Environment for Modeling and Design of Integrated Biochemical Processes, Computers and Chemical Engineering, 18 (SS): S621-S625. 
Petrides, D.P., E. Sapidou, and J. Calandranis (1995). Computer-Aided Process Analysis and Economic Evaluation for Biosynthetic Human Insulin Production - A Case Study, Biotechnology and Bioengineering, 5, 529-541.

Reisman, H.B. (1988). Economic Analysis of Fermentation Processes. CRC Press, Inc., Boca Raton, Fla.

Roberts L.R. (1979). In Encyclopedia of Chemical Processing and Design, 8, Marcel Dekker, New York, 324-333.

Seaver, S.S. (1997). Monoclonal Antibodies: Using New Techniques to Reduce Development Time. Genetic Engineering News, 17, No. 1, 13-28.

Seider, W.D., J.D. Seader, and D.R. Lewin (1999). PROCESS DESIGN PRINCIPLES Synthesis, Analysis, and Evaluation, John Wiley \& Sons, New York.

Smith G.L. (1994). Large Scale Animal Cell Culture, in Bioprocess Engineering (B.K. Lydersen, N.A. D'Elia, and K.L. Nelson ed.), Wiley Interscience, New York, 69-84.

Taylor, G., M. Hoare, D.R. Gray, and F.A.O. Marston (1986). Size and Density of Protein Inclusion Bodies, Bio/Technology, 4, June.

Ulrich, G.D. (1984). A Guide to Chemical Process Design and Economics, John Wiley \& Sons, Inc.

Valentino, F.W. and G.E. Walmet (1986). Industrial Waste Reduction: The Process Problem. Environment. 28, 16-34.

Valle-Riestra, J.F. (1983). Project Evaluation in the Chemical Process Industries, McGraw-Hill, NY.

Wheelwright, S.M. (1987). Designing Downstream Processes for Large-Scale Protein Purification, Bio/Technology, 5, 789-793. 